\title{
EL MONASTERIO DE SANTA MARÍA DE HUERTA ENTRE LOS SIGLOS XII Y XVI: RELACIONES CON ARAGÓN Y CON LOS PODERES NOBILIARIOS REGIONALES*
}

\author{
POR \\ MÁxIMO DIAGO HERNANDO ${ }^{1}$ \\ Instituto de Historia, CSIC. Madrid
}

\section{RESUMEN}

El autor reconstruye la trayectoria de un monasterio cisterciense, el de Santa María de Huerta, desde su fundación a comienzos del siglo XII hasta su incorporación a la Congregación observante del Císter a principios del siglo XVI. Pone de manifiesto los efectos que tuvo para su evolución en sus primeros siglos su ubicación en una comarca fronteriza, entre los reinos de Castilla y de Aragón. Y presta también atención a otro aspecto fundamental de su trayectoria medieval, el de las relaciones establecidas por la comunidad monástica con los poderes nobiliarios, y en concreto con el linaje de los Finojosa, hasta comienzos del siglo XIV, y a partir de la época Trastámara con el de los señores de Medinaceli. En última instancia, trata de ilustrar con un ejemplo concreto, el proceso en virtud del cual los monasterios cistercienses fueron perdiendo su vocación «paneuropea» para terminar quedando reducidos a actores de segunda fila de los escenarios sociopolíticos regionales en sus respectivos reinos.

PALABRAS CLAVE: Císter; monasterios fronterizos; Castilla; Aragón; Baja Edad Media.

\section{THE MONASTERY OF «SANTA MARÍA DE HUERTA» BETWEEN THE TWELFTH AND THE SIXTEENTH CENTURIES. RELATIONSHIP WITH ARAGÓN AND WITH THE REGIONAL NOBLE POWERS}

\begin{abstract}
The author traces the history of the Cistercian monastery of Santa María de Huerta, since its foundation at the beginning of the twelfth century until its admission into the Castilian Cistercian Observant Congregation at the beginning of the sixteenth century. He exposes the main effects that its location in a border region, between the kingdoms of Castile and Aragon, exercised upon its evolution during the first centuries of its history. He also pays attention to another important aspect of its medieval trajectory, the relationships that the monastic community established with the local nobility, in particular with the members of the Hinojosa lineage, until the beginning of the fourteenth century, and with the dukes of Medinaceli, since the Trastamara period. Ultimately the author tries, with the annalysis of a single case, to offer an illustration of the proccess that brought the Cistercian monasteries to lose their pan-European vocation ending up reduced to a position of second-rank actors in the social and political regional stage.
\end{abstract}

KEY WORDS: Order of Citeaux; Monasteries in border regions; Castile; Aragon; Late Middle Ages.

CÓMO CITAR ESTE ARTículo / CITATION: Diago Hernando, M. 2018. «El monasterio de Santa María de Huerta entre los siglos XII y XVI: relaciones con Aragón y con los poderes nobiliarios regionales». Hispania Sacra 70, 141: 267-282. https://doi.org/10.3989/ hs. 2018.020

$\begin{array}{ll}\text { Recibido/Received } & 01-02-2016 \\ \text { Aceptado/Accepted } & 10-02-2016\end{array}$

\footnotetext{
* Este trabajo ha sido realizado en el marco del proyecto de investigación titulado «Identidades, contactos, afinidades. La espiritualidad en la Península Ibérica. (Siglos XII-XV)», financiado por el Ministerio de Economía y Competitividad. Referencia: HAR2013-45199-R.

1 maximo.diago@cchs.csic.es / ORCID iD: http://orcid.org/00000003-2118-5086
}

Durante el período medieval ni las naciones ni los Estados existían con las características que los hemos conocido quienes hemos vivido el tránsito entre los siglos $X X$ y $X X I$, a pesar de que determinadas corrientes políticas e historiográficas se han esforzado por buscar en dicho período sus orígenes. Por el contrario, entonces tuvo prioridad en el ámbito de civilización cristiana de obediencia 
latina el sentimiento de pertenencia a una comunidad universal, que agrupaba al conjunto de los cristianos, en la que prevalecía el sentimiento de lealtad primaria hacia la máxima autoridad espiritual representada en el papa de Roma. Y sólo a partir del siglo XII se iniciaría un proceso de secularización de este extenso ámbito de civilización que propició que este sentimiento de pertenencia a una comunidad universal terminase siendo desplazado por otro en que el sentimiento de lealtad primaria se desplazó hacia los poderes seculares y los "Estados», en su mayoría monárquicos, que se terminaron consolidando a lo largo y ancho de Europa. ${ }^{2}$

La Orden del Císter surgió en un momento en que apenas se había iniciado este proceso de secularización que terminó provocando la fragmentación política del continente europeo en compartimentos estancos donde primaba el sentimiento de pertenencia a una comunidad política presidida por una autoridad secular. Su rápida expansión a todo lo largo y ancho del espacio europeo de obediencia latina se explica en este contexto de pervivencia de la conciencia de la pertenencia a una comunidad universal, definida por su sumisión a una misma autoridad, la del papa de Roma. El propio régimen de organización de la Orden contemplado en la Charta Caritatis asumió este modelo, en virtud del cual todas las casas repartidas a lo largo y ancho del continente quedaban sometidas a una única autoridad central, la del abad de Citeaux. Pero al mismo tiempo se propiciaba el establecimiento de lazos y contactos de todo tipo entre todas las casas, gracias a las relaciones de filiación que debían mantener los monasterios con sus casas fundadoras, y a la obligatoriedad de la asistencia de todos los abades al Capítulo General, de celebración anual, en el que se tomaban las principales decisiones sobre el gobierno de la Orden. ${ }^{3}$

Los avances del proceso de secularización de la sociedad europea paralelos al proceso de surgimiento y consolidación de los Estados monárquicos, no podían, sin embargo, dejar de ejercer una fuerte influencia sobre este originario régimen de funcionamiento de la Orden del Císter, que poco a poco fue perdiendo su carácter pan-europeo. Lekai en su magnífica obra de síntesis ha dado cuenta a grandes rasgos de este proceso, llamando la atención sobre hechos fundamentales, tales como el progreso de la injerencia de los poderes nobiliarios y principescos en las grandes comunidades monásticas cistercienses centroeuropeas durante el período bajomedieval, y la posterior aparición y consolidación de las congregaciones de observancia, que sin duda devolvieron parte del vigor perdido a la Orden, pero al mismo tiempo conllevaron la renuncia a su vocación unitaria y cosmopolita. ${ }^{4}$

Con el objeto de comprobar en qué medida estas grandes tendencias se plasmaron en la evolución de los monasterios cistercienses hispanos, nos hemos propuesto en el presente trabajo trazar la historia desde esta perspectiva de uno de ellos en particular, el de Santa María de Huerta, en la actual provincia de Soria. Lo hemos escogido por tratarse de un interesante caso para profundizar en el análisis

\footnotetext{
2 Strayer 1988: 102-125.

3 Entre la abundante bibliografía existente sobre la Orden del Císter cabe destacar Eberl 2002; Pacaut 1993; Lekai 1977; Tobin 1995; Burton 2011.

4 Lekai 1977.
}

de la evolución de las relaciones que las casas del Císter mantuvieron durante el período bajomedieval con los poderes seculares, en particular los Estados monárquicos en proceso de construcción y los poderes nobiliarios con fuerte implantación a nivel regional. En efecto, se trata de una casa surgida con evidente vocación "paneuropea», pues fue fundado por iniciativa de un monarca castellano, pero se puso en marcha gracias a la llegada de monjes franceses, procedentes de la abadía de Berdones. ${ }^{5} \mathrm{Y}$, además, debido a que éstos se instalaron en un espacio inmediatamente próximo a la frontera con Aragón, mostró desde sus orígenes una decidida orientación hacia este vecino reino, donde obtuvo un importante patrimonio, y donde se esforzó por mantener fluidas relaciones políticas con sus gobernantes seculares.

\section{LA PROYECCIÓN DEL MONASTERIO HACIA EL REINO DE ARAGÓN}

La localización del monasterio en un paraje inmediatamente próximo a la frontera con Aragón, primero en Cántabos y poco después en Huerta de Ariza, le predestinó para constituirse como una comunidad con proyección simultánea en dos reinos, muy en particular en las primeras fases de su historia, durante los siglos XII y XIII, cuando las fronteras entre reinos cristianos eran realidades en proceso de definición, muy maleables. ${ }^{6}$

Así, aunque la iniciativa para la fundación correspondió al monarca castellano Alfonso VII, desde el primer momento los reyes aragoneses rivalizaron con los de Castilla por la concesión de mercedes al monasterio, como si de vasallos suyos propios se tratase. En concreto Alfonso II por un privilegio del año 1166 lo tomó bajo su protección, tutela y defensa, concediéndole que las propiedades que adquiriese en el reino de Aragón las pudiese poseer libremente, y otorgándole además la exención del pago de portazgo, lezda y herbazgo para sus ganados que circulasen por tierras de Aragón. ${ }^{7}$ En 1197, por su parte, su sucesor Pedro II expidió otro privilegio en términos muy parecidos, confirmándoles el derecho de propiedad de todas las heredades que entonces poseyesen o pudiesen poseer en el futuro, eximiéndoles del pago de portazgo, y concediéndoles que sus rebaños pudiesen pastar libremente en todos sus reinos sin pagar herbaje. Pero todo esto fue concedido en contraprestación por haber sido acogido dicho monarca por la comunidad monástica en su hermandad, para participar de los beneficios espirituales que de las oraciones y otros sacrificios de los monjes pudiesen derivarse. ${ }^{8}$

Además de estas mercedes de carácter genérico, los monarcas aragoneses también concedieron algunos bienes tangibles al monasterio, para engrosar sus fuentes de ingresos. Entre dichas concesiones cabría destacar la que efectuó Jaime I para ayuda a la financiación del gasto de

5 Así lo sostiene fray Salvador Parracía y Moure en su obra manuscrita conservada en AHN (=Archivo Histórico Nacional), Códices, 1295b. Más información sobre la fundación y trayectoria medieval del monasterio en Álvarez Palenzuela 1978 y Romero Redondo, Luzón y Anguita Fontecha 2005.

6 Ladero Quesada 2001: 5-49; Abulafia y Berend 2002; Bartlett y Mackay 1992.

7 García Luján 1981: doc. no. 6.

8 Ibídem: doc. no. 61, Calatayud, agosto de 1197. 
aceite en el refectorio durante la Cuaresma. Por privilegio expedido en Valencia en 1242 le hizo merced de un juro de $50 \mathrm{mrs}$. de oro de renta anual, equivalentes a 350 sueldos, que hacen 175 reales de plata aragoneses, situados sobre la contribución que abonaban al rey los vecinos de la Comunidad de aldeas de Calatayud el día de San Martín de cada año. ${ }^{9}$ Por fin, los monarcas aragoneses también incentivaron a algunos de sus súbditos para que hiciesen mercedes a Huerta. Así, por ejemplo, Alfonso II rogó al obispo de Tarazona, Don García, que otorgase algún beneficio a este monasterio, y, en cumplimiento de la voluntad regia, éste le concedió la exención del pago de diezmos por las viñas que poseía en términos de su obispado. ${ }^{10}$

Siguiendo el ejemplo de sus reyes, fueron muchos los laicos y religiosos residentes en las comarcas aragonesas de frontera, en especial del valle del Jalón, que donaron propiedades a Santa María de Huerta. ${ }^{11} \mathrm{Y}$ gracias a estas donaciones, y a otras inversiones realizadas en la compra de tierras y viñas con dinero de diversas procedencias, el monasterio llegó a reunir en tierras aragonesas un patrimonio relativamente importante para una institución que estaba sometida a la jurisdicción del rey de Castilla, aunque amparada por el fuero eclesiástico. En concreto llegó a poseer propiedades en los términos de Bubierca, donde se constituyó un priorato con un prior residente en un edificio perteneciente al monasterio, Terrer, Ateca, Ariza, Bordalba, Pozuel de Ariza y Monreal de Ariza. Pero el elemento patrimonial más destacado con el que llegó a contar en territorio aragonés fue, sin duda, el lugar de Torrehermosa, pues allí el monasterio castellano tuvo reconocido el ejercicio de la jurisdicción civil. Además era propietario de un horno ${ }^{12}$, y de numerosas tierras de labranza cuyo usufructo cedió a censo perpetuo a los vecinos del concejo el abad Pedro en 1266, el mismo año de la adquisición del señorío, a cambio de la entrega de una cantidad fija en cereal y dinero. ${ }^{13}$

9 El privilegio original, fechado en Valencia, 12-X-1242, y concedido al monasterio y a su abad Pedro, en AHPS (=Archivo Histórico Provincial de Soria), carp. 2-10.

10 García Luján 1981: doc. no. 60. Junio de 1196. García, obispo de Tarazona, y su cabildo renuncian a cobrar el diezmo en las viñas que el abad Jimeno y los monjes de Huerta poseen en términos del obispado, bajo ciertas condiciones, y a cambio del pago de un censo simbólico de un maravedí anual. Se justifica la merced, entre otras razones, «pro redemptione anime boni Aragonensium Ildefonsi regis cuius precibus hac ex parte facere teneor». Álvarez Palenzuela, que toma la noticia de los Anales de Manrique, sostiene que Alfonso II de Aragón, que murió el 25-IV-1196, en sus últimas voluntades había rogado al obispo de Tarazona que otorgase algún beneficio a Huerta, y en cumplimiento de la voluntad regia, el obispo Don García le concedió la exención del pago de diezmos por las viñas de Ateca. Álvarez Palenzuela 1978: 159.

11 La mayor parte de la información disponible sobre la identidad de las propiedades que el monasterio de Huerta tuvo en el reino de Aragón, y sobre cómo fueron adquiridas, puede encontrarse en AHN, Códices, 1295b.

12 En el archivo del actual monasterio de Huerta se conserva un documento fechado en 23-IV-1581, por virtud del cual el monasterio, con licencia de su general, fray Miguel de Vitoria, da a censo perpetuo al concejo de Torrehermosa el horno que poseía en dicho lugar, y ciertos derechos que disfrutaba por razón del oficio de la almotazanía, a cambio de la entrega de un censo anual de 132 sueldos jaqueses.

${ }_{13}$ Entre los documentos que conserva el actual monasterio de Huerta en su archivo hay un traslado del siglo XVIII del documento del año 1266 por virtud del cual el abad Pedro cedió a censo perpetuo a sus vasallos pobladores de Torrehermosa las tierras del dicho lugar y de El
Tanto en la Corona de Castilla como en gran parte de Europa, los monasterios cistercienses, por contraste con los monasterios benedictinos, desarrollaron en muy escasa medida la faceta de señores de vasallos, Es decir, poseyeron en sus patrimonios muy pocos señoríos jurisdiccionales. El monasterio de Santa María de Huerta participó también de esta característica, pues apenas contó con vasallos propios, en notorio contraste con otros monasterios benedictinos situados más al norte, como San Millán de la Cogolla o Santa María de Nájera, entre otros, que ejercieron señorío jurisdiccional sobre multitud de villas y aldeas dispersas por un extenso espacio territorial. ${ }^{14}$ En rigor Santa María de Huerta sólo tuvo sometidos a su jurisdicción a los vecinos del barrio que se constituyó en torno al edificio monástico, donde residían los labradores que trabajaban las tierras que poseía el monasterio. Estos individuos y sus familias tenían reconocida la condición de renteros o colonos, y no llegaron a adquirir el derecho de constituirse como comunidad política en sentido estricto, pues no se les permitió formar concejo, sino que estaban obligados a someterse a la jurisdicción del alcalde mayor nombrado por el monasterio. ${ }^{15}$ Fuera de Huerta, el monasterio poseyó algunos otros términos compactos en territorio de la Corona de Castilla, como Albalate, Arandilla Boñices, Cántabos o Bliecos, pero ninguno de ellos puede ser calificado como señorío jurisdiccional propiamente dicho, por más que la documentación a veces proporciona informaciones imprecisas o contradictorias al respecto. ${ }^{16}$

Esta escasez de vasallos en territorio de la Corona de Castilla, paradójicamente, pudo compensarla en parte el monasterio desde fecha temprana mediante la adquisición del ya mencionado señorío jurisdiccional de Torrehermosa en el reino de Aragón. Este lugar había formado parte inicialmente de la Tierra de Ariza y fue desmembrado por el rey Jaime I en 1256 de dicha jurisdicción, para donarlo al noble Don Pedro de Narbona, con su correspondiente término, que fue delimitado, siguiendo órdenes del rey, por la justicia y jurado de Ariza con otras personas de dicha villa y de Monreal. Diez años después, sin embargo, el hermano y heredero de Pedro de Narbona, llamado Alonso Pérez de Ariza, acordó con el monasterio de Huerta el trueque del lugar con su jurisdicción a cambio de toda la heredad que éste poseía en Embid de Ariza, que había sido donada por un vecino de Ariza a San Martín de Finojosa cuando era abad. El monarca aragonés confirmó este trueque, y de este

Pechuelo. También conserva otro documento que recoge una concordia firmada el 26 de octubre de 1444 entre el abad Gonzalo de Heredia y el convento de Huerta, de una parte, y el concejo de Torrehermosa, de otra, por la que se comprometieron a observar el contrato firmado en 1266 por el abad Pedro de Huerta, y Ruy Martínez de Fariza, en virtud del cual el monasterio cedió a censo perpetuo sus posesiones en la villa de Torrehermosa a sus pobladores, excepto el horno. Por fin, también conserva un traslado de una sentencia arbitral que sobre la observancia de este mismo contrato pronunció el abad del monasterio de Piedra en 1471.

14 Diago Hernando 1996: 85-107.

15 Así se hizo constar a mediados del siglo XVIII en el Catastro de Ensenada, según el cual vivían entonces 23 vecinos labradores en el barrio de Huerta. Vid. Alcalde Jiménez 1996: 177. A comienzos del siglo XVI se atribuían 30 vecinos pecheros a dicho barrio, adscrito al monasterio. Vid. Carretero Zamora 2008: vol. 1, 154.

16 Analiza en detalle esta cuestión, Ávila Seoane 2009: vol. 1, 313-330. 
modo los monjes cistercienses de Huerta se convirtieron en señores de vasallos en el reino de Aragón, manteniendo esta condición hasta el año 1597. Entonces decidieron vender Torrehermosa con su jurisdicción a Don Juan Manuel Zapata, vecino de Calatayud, gentilhombre de la boca del rey, en precio de 8.000 escudos, si bien reservándose la propiedad de algunas tierras en su término. ${ }^{17}$ Cabe precisar, no obstante, que el monasterio sólo pudo ejercer la jurisdicción civil sobre este lugar, puesto que la jurisdicción criminal, en casos «de sangre», continuó perteneciendo a la villa de Ariza, y finalmente a la familia de origen catalán de los Palafox desde que en 1381 Pedro IV de Aragón vendió este señorío a Guillem de Palafox. ${ }^{18}$

La posesión durante más de tres siglos de este enclave jurisdiccional en territorio aragonés por un monasterio que estaba sometido a la autoridad del rey de Castilla no podía dejar de generar problemas para el propio monasterio y sus vasallos aragoneses, sobre todo durante el período bajomedieval, cuando abundaron los enfrentamientos entre las monarquías castellana y aragonesa. Como prueba baste recordar que en varias ocasiones los monarcas aragoneses otorgaron a súplica del monasterio de Huerta cartas dirigidas a las autoridades del concejo de Ariza para que no permitiesen que los vecinos de Torrehermosa sufriesen injurias por razón de la defensa de sus términos, y les ayudasen cuando lo precisasen. Así lo hizo, por ejemplo, Jaime II en 1312, cuando el monasterio de Huerta acudió a denunciarle que muchos vecinos de los lugares de la frontera de Castilla injuriaban a los de Torrehermosa por razón de los términos. ${ }^{19} \mathrm{Y}$ lo volvió a hacer, nada más acceder al trono, su sucesor Alfonso IV en 1328, en respuesta a las denuncias por injurias sufridas en la defensa de sus términos que le habían hecho llegar los vecinos de Torrehermosa. ${ }^{20}$

Los problemas que se derivaban de la existencia de este enclave no los sufrieron, sin embargo, sólo los vasallos del monasterio allí residentes, más expuestos a los abusos de los aragoneses. Por el contrario también de parte aragonesa se elevaron quejas por los peligros que de la existencia de esta suerte de avanzada castellana se derivaban para la preservación de la plena soberanía del rey de Aragón en su reino. Un ilustrativo testimonio nos lo proporciona una carta que en 1383 dirigió el monarca aragonés al abad de Huerta recriminándole por haber cedido el lugar de Torrehermosa a un caballero castellano, Gonzalo Sánchez de Cavanillas, quien desempeñaba el oficio de alcalde y guarda de las sacas por el rey de Castilla. ${ }^{21}$ Los motivos por los que el abad había efectuado la cesión los desconocemos, ni si había mediado alguna contraprestación en la forma de entrega de algún censo en dinero o en especie para engrosar los ingresos del monasterio. Pero el rey de Aragón entendía que la misma estaba amenazando directamente su soberanía, porque dicho caballero, siendo además oficial del rey de Castilla encargado de vigilar las salidas y entradas de mercancías,

\footnotetext{
17 AHN, Códices, 1295b.

18 Vid. Redondo Veintemillas y Sarasa Sánchez 1988: 31-50.

19 ACA (=Archivo de la Corona de Aragón), C (=Cancillería), reg. (=registro) 150-4, Barcelona, 15-VII-1312. Carta a la justicia, jurados y concejo de Ariza.

20 ACA, C, reg. 428-237v, Zaragoza, 16-IV-1328.

21 Carta del rey de Aragón al abad de Huerta recriminándole por su proceder, en ACA, C, reg. 1104-49v, Tortosa, 27-III-1383.
}

había decidido trasladar su residencia a Torrehermosa, donde incluso tenía intención de edificar una fortaleza. Y todo esto equivalía en la práctica a incorporar dicho lugar al territorio sobre el que ejercía su soberanía el monarca castellano, alterando de facto la línea fronteriza.

Desconocemos cómo se resolvió este incidente con Gonzalo Sánchez de Cavanillas, quien cabe presumir que terminase devolviendo la plena posesión de Torrehermosa al monasterio de Huerta, pues consta que éste la disfrutaba con normalidad durante la primera mitad del siglo XV. Entonces de nuevo se volvieron a elevar quejas contra el abad de Huerta y sus vasallos de Torrehermosa por parte de los súbitos aragoneses avecindados en la Tierra de Ariza. En concreto en 1441 la reina María, gobernadora de Aragón en nombre de su marido ausente en Nápoles, recriminó en una carta al abad de Huerta por estar causando todo tipo de vejaciones a los vecinos de Ariza y sus aldeas, amenazándoles con cartas de marca y con tomarles sus bienes, como represalia porque un criado suyo, un mozo natural de Ariza, había abandonado su servicio. ${ }^{22}$ Pese a esta intervención de la propia reina, las tensiones entre el abad de Huerta y los vecinos de Ariza continuaron, alentadas sin duda por la pasividad del conde de Medinaceli, que, según denunció la reina en cartas que le dirigió a él y al rey de Castilla, estaba implícitamente consintiendo los desmanes perpetrados por el abad contra los de Ariza. No concebía la reina, en efecto, que nada pudiese acometer el abad en aquella comarca en contra de la voluntad del conde, y así lo manifestó explícitamente, haciendo recaer en éste la responsabilidad de cuanto estaba sucediendo.

$Y$, efectivamente, otros indicios confirman que no iba muy desorientada la reina, pues pocos años después, en 1444 , volvió a dirigirse por carta a este poderoso noble castellano, para recriminarle el hecho de haber puesto un alcaide en Torrehermosa. ${ }^{23}$ Se habría vuelto, pues, a reproducir la situación del año 1383, cuando el alcalde de sacas Gonzalo Sánchez de Cavanillas se había instalado en la mencionada aldea aragonesa con la intención de edificar allí una fortaleza. Pero en esta ocasión el desafío a la soberanía aragonesa sobre su propio territorio era de mayor gravedad, puesto que el poderío del conde de Medinaceli en la región era más de temer que el de un simple alcalde de sacas. En efecto, la reina en aquella ocasión no sólo mostró su preocupación por el peligro de la pérdida de la soberanía sobre Torrehermosa, sino también por la amenaza que suponía el que este lugar se llegase a consolidar como una punta de lanza en territorio aragonés, desde el que uno de los nobles castellanos más poderosos en la comarca de la frontera pudiese lanzar ataques indiscriminados sobre los aragoneses. Y así se lo reprochó en términos muy explícitos en su carta al propio conde, en la que le recriminó por las «novedades» que cada día intentaba introducir en la frontera, y por las amenazas que estaba lanzando contra los vecinos de Ariza.

La posesión del señorío de Torrehermosa fue en cualquier caso un elemento fundamental para empujar al monasterio de Huerta a verse implicado en los asuntos de

22 Carta de la reina María al abad de Huerta, en ACA, C, reg. 3180 81, Alcañiz, 1-VI-1441.

${ }_{23}$ Carta de la reina María al conde de Medinaceli, en ACA, C, reg. 3190-96v, Valencia, 26-VI-1444. 
Aragón, y que propició que en aquel sector de la frontera castellano-aragonesa ésta mostrase una mayor porosidad de la habitual, que se puso de manifiesto, por ejemplo, en las frecuentes violaciones de la misma que provocaron las entradas violentas de grupos de hombres armados de Castilla en Aragón, y viceversa. Como ejemplo de este tipo de incidentes baste recordar el denunciado a comienzos del año 1524 por el monasterio de Huerta ante el monarca castellano Carlos I. Acusó al señor de Ariza, Francisco de Palafox, a Francisco de Mendoza, Andrés de Orozco y otras personas, de haber entrado primero con gente armada desde el reino de Aragón en término de Castilla, llevándose consigo presos a dos monjes del monasterio a una fortaleza de Aragón, y de haber salido en una segunda ocasión, el 19 de septiembre de 1523, desde Monreal de Ariza con mucha gente armada para entrar en el monasterio de noche, cuando los monjes estaban durmiendo, quebrantar las puertas y cometer varios atropellos, tras lo cual regresaron a Aragón. ${ }^{24}$

PROTECCIÓN DE LOS INTERESES DEL MONASTERIO DE HUERTA POR LOS MONARCAS ARAGONESES DURANTE EL PERÍODO BAJOMEDIEVAL

La preservación de su patrimonio en Aragón por parte del monasterio de Huerta se vio en gran medida facilitada por la actitud protectora que los monarcas aragoneses continuaron mostrando hacia él durante los siglos XIV y $\mathrm{XV}$, pese al evidente deterioro de las relaciones políticas entre los reinos de Castilla y Aragón que se produjo en estas centurias, en que se sucedieron varias guerras. Por supuesto, el monasterio no resultó incólume, y en momentos críticos sufrió graves perjuicios por poseer una parte de su patrimonio en Aragón. Pero no cabe duda de que habría resultado mucho más perjudicado si los monarcas aragoneses hubiesen adoptado una actitud más hostil hacia él por tratarse de un monasterio castellano.

Al tratar del señorío de Torrehermosa hemos tenido ocasión de aludir a intervenciones de monarcas aragoneses en defensa de los intereses de Santa María de Huerta, como las de Jaime II en 1312 y Alfonso IV en 1328, instando a sus súbitos, los oficiales de Ariza y su Tierra, para que no permitiesen que los vecinos de dicho lugar, que eran vasallos del monasterio castellano, sufriesen daños por razón de la defensa de sus términos, e incluso les protegiesen y proporcionasen ayuda cuando la requiriesen.

Por otro lado, estos mismos monarcas en más de una ocasión tuvieron que intervenir para que se hiciesen respetar los privilegios que ellos y sus antecesores habían concedido a Santa María de Huerta, ante la reticencia de algunos de sus oficiales. Ocurrió, por ejemplo, en la comarca de Calatayud y Ariza, donde se concentraba el patrimonio aragonés del monasterio. Allí tropezó éste con problemas para que se le respetase el privilegio de la exención del pago de ciertos impuestos al tránsito de bienes y mercancías, como el peaje y el pontaje, cuando los bienes circulantes fuesen propios de la comunidad monástica, y no de otro dueño. Por ello Jaime II en 1319 llegó a conminar a los peajeros de Ariza y

24 AGS (=Archivo General de Simancas), RGS (=Registro General de Sello), II-1524 (2으).
Calatayud a que no cobrasen peaje ni pontaje cuando en sus distritos se transportasen bienes o mercancías propias del monasterio de Huerta. ${ }^{25} Y$ se vio obligado a reiterar la orden al año siguiente, porque los peajeros insistían en continuar exigiendo el pago del impuesto cuando las mercancías eran transportadas en bestias que no eran propias el monasterio. ${ }^{26}$

En otras ocasiones, la comunidad monástica hortense no dudó en recurrir ante los monarcas aragoneses en busca de protección, cuando consideró que sus oficiales la sometían a exacciones fiscales injustificadas por razón de su patrimonio aragonés. De ello nos proporciona testimonio una carta que Pedro IV el Ceremonioso dirigió al abad de Huerta en marzo de 1344, en respuesta a la denuncia que éste había presentado contra el caballero aragonés Pedro Martínez de Azagra por querer obligar al monasterio a pagar a la Curia aragonesa 2.000 sueldos jaqueses por razón de sus bienes. ${ }^{27}$

Durante los períodos en que hubo guerra declarada entre los reinos de Castilla y Aragón no puede decirse, por supuesto, que el monasterio resultase incólume, sin sufrir las consecuencias negativas de la situación bélica reinante. Las guerras entre reinos provocaban el empobrecimiento de las comarcas fronterizas, resultando particularmente damnificados los campesinos residentes en las mismas. Y del empobrecimiento de los campesinos se derivaban necesariamente perjuicios para los monasterios a los que éstos debían entregar parte de sus cosechas en concepto de rentas y otras prestaciones. De hecho en la documentación encontramos algunos testimonios de quejas presentadas por monasterios fronterizos por el empobrecimiento en ellos provocado por la guerra. Así, un documento de febrero de 1360 recoge la queja del monasterio de Santa María de Piedra, lamentándose de haber venido a pobreza por causa de la guerra de Castilla, la llamada de los dos Pedros. ${ }^{28}$ Por otra parte también tenemos noticia de que durante esta guerra el monasterio de Santa María de Veruela llegó a ser ocupado por las tropas castellanas, que se apoderaron igualmente de la cercana ciudad de Tarazona, y, tras ser abandonado por los monjes, fue saqueado, causando notable destrucción. ${ }^{29}$ No hemos encontrado testimonios similares relativos a Huerta, pero es bastante probable que los haya, y sin duda podría haberlos habido en mayor número de haberse conservado los registros de la cancillería castellana de esta época, perdidos a diferencia de los de la cancillería aragonesa.

No obstante, llama la atención comprobar que, pese al encarnizamiento al que se llegó en el enfrentamiento entre Castilla y Aragón durante la guerra de los dos Pedros, el monarca aragonés, dando continuidad a la política protectora de sus antepasados hacia la comunidad hortense, quiso expresamente que ésta quedase excluida de las medidas de represalia aprobadas contra todos los súbditos castellanos. Así lo pone de manifiesto una carta que en marzo de 1359 dirigió a los frontaleros, oficiales y alcaide de Sisamón, y a otros alcaides y almogávares que hagan guerra en las

\footnotetext{
25 ACA, C, reg. 169-85v, Calatayud, 23-VII-1319.

26 ACA, C, reg. 170-58v, Calatayud, 23-VII-1320.

27 ACA, C, cartas reales de Pedro IV, 2.206-1. Carta de Pedro IV al abad de Huerta, de Barcelona 15-III-1344.

28 ACA, C, reg. 699-159.

29 Tomamos la referencia de Moreno Lapeña 1995.
} 
fronteras de Aragón, en la que les reprendió por haber tomado presos a algunos monjes de este monasterio, y les ordenó que los liberasen y les devolviesen sus bienes, pues no era su intención que se hiciese guerra contra los monjes o cualquier otro religioso. ${ }^{30}$

En otros momentos de enfrentamiento bélico con Castilla, la monarquía aragonesa también nos consta que adoptó una política protectora hacia la comunidad de Huerta. Muy reveladora resulta desde este punto de vista la concesión de una carta de guiaje por Jaime II en marzo de 1296, por la que tomó bajo su protección dicho monasterio y sus bienes, asegurándolos frente a potenciales atacantes. ${ }^{31}$ Dicha concesión coincidió, además, con el momento del inicio de una guerra contra la monarquía castellana, representada en el niño Fernando IV, frente al que el monarca aragonés asumió la defensa de los intereses dinásticos de los infantes de la Cerda, con el objetivo evidente de anexionarse el reino de Murcia.

Por supuesto, también tenemos constancia de que, en determinadas ocasiones, esta dispensación de un trato excepcional al monasterio de Huerta, eximiéndolo de las medidas de represalia habitualmente decretadas contra los súbditos del enemigo, no se aplicó. Y paradójicamente el testimonio más claro que de ello hemos encontrado en la documentación corresponde a una de las guerras menos cruentas de las que a lo largo de los siglos XIV y XV opusieron a los reinos de Castilla y Aragón, la que inició Alfonso $V$ en 1429 contra su primo Juan II. En efecto, nos consta que, a raíz de la declaración de guerra, el monarca aragonés ordenó embargar todos los bienes que poseía en Aragón el monasterio de Huerta. Pero fue un embargo de muy corta duración porque poco después se firmaron treguas con los castellanos, y Alfonso $\mathrm{V}$ decidió levantarlo, y ordenó de inmediato a los justicias, jurados y otros oficiales de Ateca y Bubierca, aldeas de Calatayud, que se le devolviesen al monasterio los bienes que le hubiesen sido tomados, y se le continuasen pagando sus rentas y todos los frutos que le perteneciesen. ${ }^{32}$

Para explicar esta mayor dureza en la actitud demostrada por el monarca aragonés hacia la comunidad cisterciense de Huerta en 1429, al iniciarse la guerra, ha de tenerse en cuenta que el monasterio fue utilizado al parecer por los castellanos como base de operaciones bélicas. Así lo sugiere al menos la noticia que proporciona Jerónimo Zurita en sus Anales, informando sobre la entrada que efectuó en Aragón el Condestable Don Álvaro de Luna desde Huerta con 1.500 hombres de armas y jinetes, «talando y quemando todo lo que alcanzaba». ${ }^{33}$ Teniendo en cuenta la influencia creciente que, como veremos, los condes de Medinaceli iban ejerciendo sobre la comunidad hortense conforme avanzaba el siglo XV, no hay que descartar que por este motivo en aquellos momentos dicha comunidad fuese considerada por el monarca aragonés y sus hermanos, los infantes de Aragón, radicalmente enfrentados con Don Álvaro de Luna, como "enemigo político», y como tal la tratasen. En última

30 ACA, C, reg. 1168-52v, Calatayud, 26-III-1359.

31 ACA, C, reg. 108-120, Calatayud, 8-III-1296.

32 ACA, C, reg. 2580-107v, La Almunia, 9-VIII-1430. Sobre los efectos que tuvo esta guerra en la comarca fronteriza donde se ubicaba Huerta Vid. Diago Hernando 2013: 304-312.

33 Zurita 1980: vol. 5, 705. instancia no debemos olvidar que más que una guerra entre reinos, lo que entonces se estaba ventilando era una lucha por el poder entre dos facciones de la alta nobleza castellana, en la que se había visto arrastrado el reino de Aragón.

Por supuesto, en el estado actual de la investigación resulta arriesgado llegar a conclusiones seguras sobre los efectos que las guerras entre Castilla y Aragón tuvieron sobre el patrimonio aragonés del monasterio de Huerta, porque las noticias reunidas, aunque significativas, son pocas y demasiado fragmentarias. No hay que descartar, por ejemplo, que en algún momento Pedro el Ceremonioso, como reacción ante la dureza de los ataques de su pariente de Castilla a comunidades religiosas aragonesas como la de Veruela, tomase alguna medida de represalia contra dicho patrimonio. Pero, no sin cierta precaución, consideramos justificado concluir que la escasez de testimonios sobre consecuencias catastróficas de dichas guerras para las propiedades de los cistercienses de Huerta en Aragón demostraría que el proceso de consolidación de los reinos ibéricos como entidades políticas diferenciadas que tuvo lugar durante los siglos bajomedievales no afectaría todavía de forma irreversible en sus primeras fases a aquellas comunidades eclesiásticas con mayor vocación transnacional. El apoyo expreso de los reyes, todavía no imbuidos de una excluyente mentalidad "nacionalista», les habría permitido a dichas comunidades, y muy en particular a Huerta, mantener esta vocación, aunque, por supuesto, con un vigor decreciente.

\section{LAS RELACIONES DE HUERTA CON LOS MONASTERIOS CISTERCIEN- SES ARAGONESES PRÓXIMOS A LA FRONTERA}

El monasterio se puso en funcionamiento gracias a la llegada de un puñado de monjes venidos de Francia, que se instalaron en un espacio de frontera, donde se estaban fraguando dos reinos, el de Castilla y el de Aragón, cuyo espacio jurisdiccional se encontraba todavía en proceso de conformación, aunque tampoco experimentó alteraciones sustanciales con posterioridad. Estas circunstancias favorecieron sin duda que en sus primeros tiempos se desarrollase como una comunidad sin una marcada adscripción nacional. El propio modelo de organización de la Orden del Císter a partir de la entrada en vigor de la Charta Charitatis lo favorecía. En efecto, como bien nos informa Lekai en su magnífica obra de síntesis, con la misma se logró un feliz equilibrio entre autoridad central y autonomía local, que hizo posible la consolidación de una extensa red de monasterios que abarcaba prácticamente todo el territorio europeo de obediencia romana. Estos monasterios mantenían estrechos vínculos entre sí gracias a las relaciones de filiación que unían con frecuencia a casas ubicadas en distintos reinos, y a la dependencia de todas las casas del abad de Citeaux, que conllevaba la obligación para todos los abades de acudir cada año a una asamblea o Capítulo General, que ofrecía un contrapeso a la por lo demás ilimitada autoridad reconocida al abad de Citeaux. La obligatoriedad de las periódicas visitas de los monasterios por los abades de otras casas situadas por encima en la jerarquía que establecían las relaciones de filiación, también contribuía a mantener la cohesión de la Orden, impidiendo que se impusiesen las tendencias centrífugas 
que favoreciesen el aislamiento de los monasterios. ${ }^{34}$

Los condicionamientos geográficos, en un período como el medieval en el que la tecnología no se había desarrollado lo suficiente como para favorecer los rápidos desplazamientos a largas distancias, propiciaban, no obstante, que los contactos se intensificasen en mayor medida con aquellas comunidades que se ubicaban más cerca. Desde este punto de vista el monasterio de Huerta ofrece la peculiaridad entre todos los monasterios castellanos del Císter de que era el que, por factores geográficos, con mayor facilidad podía mantener contactos con el reino de Aragón, del que le separaba una muy pequeña distancia, y donde además reunió un importante patrimonio. Por ello merece la pena detenerse en dar cuenta de cuáles fueron las relaciones que estableció con otras comunidades cistercienses ubicadas en este reino.

De entre ellas, era la de Santa María de Piedra la que se encontraba en una situación más propicia para mantener constante contacto con la de Huerta, no sólo porque la distancia que separaba ambos monasterios era corta, sino también porque los dos poseían una parte importante de su patrimonio en la misma comarca aragonesa, en el entorno de la ciudad de Calatayud..$^{35} \mathrm{Y}$, en efecto, la documentación, pese a su carácter disperso y en exceso lacónico, proporciona indicios suficientes para concluir que durante el período bajomedieval fue la de Piedra la comunidad monástica con la que Santa María de Huerta mantuvo una más estrecha relación. Entre dichos indicios hay que destacar, por ejemplo, alguna mediación del abad de este monasterio aragonés como juez árbitro para resolver los conflictos que oponían al monasterio de Huerta con sus vasallos aragoneses de Torrehermosa. En concreto tenemos noticia de que en 1471 el abad de Piedra pronunció una sentencia arbitral para poner fin a las diferencias que habían surgido entre el monasterio de Huerta y dichos vasallos en torno al cumplimiento del contrato firmado en 1266 por virtud del cual se les había concedido a censo perpetuo el usufructo de todas las propiedades del monasterio en Torrehermosa, a excepción del horno. ${ }^{36}$ Pero a la inversa, también al abad de Huerta se le asignó un papel destacado por las autoridades apostólicas en la supervisión de la gestión que realizase de su patrimonio el monasterio de Piedra. Así, en concreto, por bula del papa Pío II del año 1459 se le designó para que fuese el encargado de informarse sobre la conveniencia de proceder a la venta o permuta de determinados bienes del mencionado monasterio aragonés, para autorizarla si redundase en provecho del mismo. ${ }^{37} \mathrm{Y}$, haciendo uso de estas atribuciones, muchos años después, en 1498, el abad de Huerta, fray Sebastián Campuzano, concedió licencia al de Piedra para enajenar ciertas heredades que su monasterio poseía en términos de Daroca, Burbáguena y otras aldeas aragonesas. ${ }^{38}$

\footnotetext{
34 Lekai 1977.

35 Sobre el patrimonio del monasterio de Piedra vid. De la Fuente Cobos 1993 e ídem 2001. Sobre su trayectoria histórica vid. Barbastro

36 El traslado de esta sentencia arbitral de 1471 se conserva entre los fondos documentales que en la actualidad alberga el monasterio.

37 La bula expedida en Mantua, 21-VIII-1459 en AHN, Clero, carpeta

38 AHN, Clero, carpeta 3727-9. Documento otorgado en Piedra,
} Gil 2000. 3727-9. 15-XI-1498.
Por su parte, también resulta sintomático que los abades de Piedra fueron designados por las autoridades apostólicas para ejercer las funciones de jueces conservadores cuando para ello fuesen requeridos por el monasterio de Huerta. Lo testimonia, por ejemplo, un documento del año 1345, por el que el abad del monasterio de Montearagón, que había sido nombrado juez conservador de la Orden del Císter por bula de Clemente VI, comisionó a los abades de Santa María de Piedra, Santa María de Veruela y Santa María de Ovila, es decir dos monasterios aragoneses y uno castellano, para que en su lugar ejerciesen las funciones de tal juez conservador cuando fuesen convocados por el abad de Huerta. ${ }^{39}$

La intensidad de las relaciones entre el monasterio de Huerta y el de Piedra queda, por fin, también puesta de manifiesto, por vía indirecta, por el hecho de que los señores de la casa de Medinaceli, que, como veremos tendieron a convertirse en patronos de facto del primero a partir del siglo XV, hicieron extensiva su devoción hacia el segundo, el único ubicado en el reino de Aragón para el que tuvieron algún tipo de recuerdo en las disposiciones piadosas de sus testamentos. Así, en el que otorgó el conde de Medinaceli en nombre de su difunta esposa, Juana Sarmiento, el 25 de febrero de 1435, dispuso que se cantasen por el alma de ésta dos treintenarios en Huerta, y un treintenario en cada uno de los siguientes monasterios e iglesias: Santa María de Piedra, Santa Clara de Tordesillas, San Benito de Valladolid, iglesia mayor de Medinaceli, Santa María del Puerto y Santa María de la Val, en La Palma. ${ }^{40}$

Otro importante monasterio cisterciense fundado en territorio aragonés a corta distancia de la frontera con Castilla fue el de Santa María de Veruela, en la comarca del Moncayo. ${ }^{41}$ Por su mayor lejanía en términos relativos, sus relaciones con Santa María de Huerta fueron, sin embargo, menos intensas que en el caso de Piedra. No obstante, cabe señalar que en la primera fase de desarrollo de ambas casas, que fueron fundadas en fechas muy próximas entre sí, en 1144 la de Huerta y en 1146 la de Veruela, encontramos indicios en la documentación que sugieren que entonces ambas mantuvieron una más íntima relación, pues Piedra no fue fundado hasta 1194. En concreto destacaríamos desde este punto de vista unos documentos del año 1200 que ponen de manifiesto que el abad de Veruela estuvo presente en momentos clave para la historia del monasterio de Huerta, cuando éste adquirió elementos fundamentales de su patrimonio, gracias a mercedes que le hicieron los miembros del linaje de los Finojosa. Así, cuando el 28 de junio de ese año Nuño Sancho y su mujer Doña Marquesa, y sus hijos Martín Muñoz y Adam, donaron a Santa María de Huerta la heredad de Albaladejo, en Tierra de Cuenca, el abad de Veruela estuvo presente como testigo, junto al obispo de Sigüenza y otros, al acto de expedición del documento, y aportó su propio sello, para que junto con los del referido obispo y el del propio Nuño Sancho el documento fuese provisto de las máximas garantías. ${ }^{42}$ Pero, además, sabemos que no se limitó a estar presente, y a aportar su sello, sino que también salió fiador del convento de Huerta, obligando

\footnotetext{
39 AHN, Clero, carpeta 3699-8.

40 Copia de este testamento en Pardo Rodríguez 1993: doc. №. 167.

41 Vid. Dailliez 1987 y Rodríguez Lajusticia 2010.

42 Documento otorgado en Huerta, 28-VI-1200, publicado por García Luján 1981: doc. №. 65.
} 
su persona a que este último cumpliría todos los términos del acuerdo al que había llegado con Nuño Sancho y Doña Marquesa, a cambio de que éstos le donasen Albadalejo. ${ }^{43}$

La reunión de los reinos de Castilla y Aragón bajo el paraguas de una misma Monarquía, de forma transitoria durante el gobierno de Isabel y Fernando, y ya de forma definitiva con el de Carlos I, no fue acompañada, sin embargo, de una intensificación de los contactos entre las casas cistercienses ubicadas a uno y otro lado de la frontera. Por el contrario todos estos monarcas trabajaron para que saliese adelante la reforma de los monasterios cistercienses de la Corona de Castilla, que finalmente propició que todos ellos quedasen integrados desde la primera mitad del siglo XVI en una misma Congregación, conformando una agrupación bien diferenciada respecto al resto de monasterios cistercienses no sólo de la península sino del conjunto de Europa. ${ }^{44}$ Por su parte los monasterios de los reinos de la Corona de Aragón, aunque con notable retraso, terminaron también siguiendo el ejemplo de sus homólogos castellanos, poniendo en marcha la llamada Congregación cisterciense de la Corona de Aragón en el año 1613, la cual poco después, en 1632, incorporó también los monasterios navarros. ${ }^{45}$ No cabe duda de que estos cambios institucionales contribuirían a debilitar las relaciones entre el monasterio de Huerta y sus homólogos de Piedra y Veruela, alentando además la pérdida de interés del primero por el ámbito aragonés, que se puso de manifiesto en la enajenación de su señorío de Torrehermosa a fines del siglo XVI. No tuvo lugar ciertamente un distanciamiento y ruptura de lazos radical, como bien lo prueba, por ejemplo, la continuidad de la presencia en la época moderna de monjes de origen aragonés en la comunidad de Huerta. Pero la actuación de los monjes de Piedra durante la guerra de Sucesión, tomando abiertamente partido a favor del archiduque Carlos $^{46}$, no deja lugar a dudas sobre el hecho de que la pertenencia a dos Congregaciones diferentes había tenido evidentes consecuencias para la orientación política de estas comunidades cistercienses de la frontera entre Castilla y Aragón que habían nacido en el siglo XII con una vocación transnacional, que se fue debilitando con el transcurso de los siglos.

LAS RELACIONES DEL MONASTERIO CON LA NOBLEZA DE LA REGIÓN SORIANA: EL CASO DEL LINAJE DE LOS FINOJOSA

Uno de los aspectos de la historia del monasterio en sus primeras fases que más se ha destacado por sus estudiosos ha sido el de su relación con el linaje noble de los Finojosa. Este hecho se explica sobre todo por la pertenencia al mismo de una de las figuras más sobresalientes de esta comunidad monástica a lo largo de su historia, el abad Martín de Finojosa, que luego fue obispo de Sigüenza y terminó siendo canonizado por la Iglesia.

Se trata de un linaje nobiliario perteneciente a la llamada nobleza vieja de la que habló el profesor Moxó en un trabajo clásico, en el que aporta someras noticias sobre

43 Sobre esta actuación del abad de Veruela como fiador informan dos documentos sin fecha, correspondientes al año 1200, que publica García Luján 1981: docs. n‥ 69 y no. 70.

44 Martín 1953: 28.

45 López 1968-1969: 207-243 y Moral 1968: 5-27.

46 Barbastro Gil 2000: 37-38. el mismo. ${ }^{47}$ Son muchos los detalles que desconocemos sobre su trayectoria histórica debido a la escasez de noticias documentales. Según todos los indicios, toma su denominación del lugar de Hinojosa de la Sierra, en la parte septentrional de la provincia de Soria ${ }^{48}$, del que sus miembros debieron ser señores entre los siglos XI y XIII. Pero nada podemos precisar sobre el origen y características de este señorío. El único hecho del que tenemos certeza es que este lugar, junto con algunas otras pequeñas aldeas a su alrededor, no formó parte en origen de la jurisdicción de la Tierra de Soria cuando los límites de ésta quedaron fijados a comienzos del siglo XII por iniciativa de su repoblador, el monarca aragonés Alfonso I. Esta circunstancia explica que dichos lugares no figuren entre las llamadas aldeas dezmeras de Soria, los nombres de las cuales conocemos en detalle gracias a una relación puesta por escrito en tiempo de Alfonso $\mathrm{X}^{49}$, si bien consta que con posterioridad terminaron incorporándose a dicha jurisdicción. En el caso en concreto de Hinojosa de la Sierra sabemos que la incorporación se produjo como consecuencia de una compra que efectuó el concejo de Soria. Así al menos lo afirmó de forma explícita este último cuando protestó ante el rey Juan II porque este había decidido apartar dicho lugar de la jurisdicción de la ciudad para entregarlo en señorío a su aposentador Rodrigo de Vera, alegando que era suyo por haberlo comprado con sus propios dineros del rey Fernando, que, por exclusión, no podía ser otro que el rey Fernando IV. ${ }^{50}$

El linaje de los Finojosa desempeñó un papel fundamental en la primera fase de desarrollo del monasterio cisterciense de Huerta, puesto que, además de proporcionarle a su más célebre abad, San Martín, elegido en 1166 , le hizo sustanciosas donaciones, que supusieron una contribución fundamental para su patrimonio. En efecto, el hermano del abad San Martín, Nuño Sancho de Finojosa, enterrado junto a su mujer, Doña Marquesa, en el propio monasterio, donó a éste importantes propiedades en la

47 Moxó y Ortiz de Villajos 1969: 131-133.

48 Prácticamente todos los autores, incluido Moxó, dan por supuesto que se trata de Hinojosa del Campo, pero la documentación inédita que hemos tenido ocasión de consultar demuestra que se trata de Hinojosa de la Sierra. Hinojosa del Campo fue siempre aldea de la Tierra de Soria, mientras que Hinojosa de la Sierra se incorporó a esta jurisdicción a principios del siglo XIV, como indicaremos.

49 Jimeno 1958: 230-270 y 365-494. Detecta algunos errores importantes en este artículo pionero, entre los que destaca la identificación como aldea de una parroquia, Higes 1958 y 1960: 97-104 y 225273. Han sido muchos los autores que con posterioridad han analizado el contenido de este mal llamado "padrón» de Alfonso X, casi siempre olvidando que se trataba de un documento puesto por escrito para resolver un problema de reparto de diezmos, y que por consiguiente no informa exactamente sobre cuáles eran los lugares sobre los que ejercía jurisdicción la ciudad de Soria, que variaron en el transcurso del tiempo, ni sobre qué número de personas residían en cada uno de ellos, sino sobre cuántos de los parroquianos de dichos lugares debían entregar parte de sus diezmos a una determinada parroquia de la ciudad de Soria.

50 Vid. Provisión de Juan II al concejo de Soria, de Madrid, 5-III-1446, que se conserva en traslado, junto con otra documentación de interés para la historia de la villa de Hinojosa de la Sierra en AChV(=Archivo de la Chancillería de Valladolid), P. C. (=Pleitos Civiles) F. (=Fenecidos) Cajas 303-1, 304-1, 305-1 y 306-1. Debe tratarse de Fernando IV, pues pocos años después de la muerte de este rey, en 1320, el concejo de Soria confirmó a Hinojosa de la Sierra y otras aldeas próximas, la donación de una dehesa que les había efectuado en su momento Doña Marquesa, la esposa de Nuño Sancho de Finojosa. Vid. Diago Hernando 1991-1992: 37-58. 
ciudad de Cuenca y su territorio, que le pertenecían por haber participado como alférez del rey Alfonso VIII en la conquista a los musulmanes de esta plaza en $1177 .{ }^{51} \mathrm{El}$ propio San Martín, y otros miembros de su familia, en particular su madre, Doña Sancha Gómez ${ }^{52}$, y su sobrino, el célebre arzobispo de Toledo, Rodrigo Jiménez de Rada ${ }^{53}$, donaron propiedades de notoria importancia en la comarca soriana entre las que podrían destacarse los términos de Cántabos, Boñices, Albalate o Algondrón, con la dehesa de Alcardenche. ${ }^{54}$ Y la estrecha vinculación que todos estos individuos establecieron con esta comunidad cisterciense tuvo su más visible traducción en la elección por todos ellos de su iglesia como lugar de enterramiento.

Para la fase posterior a la muerte del arzobispo Jiménez de Rada, no encontramos información en la bibliografía sobre cómo evolucionaron las relaciones del linaje de los Finojosa con el monasterio hortense. Las fuentes documentales son poco generosas en informaciones, y no permiten identificar con detalle, ni mucho menos caracterizar en profundidad, a los principales representantes de dicho linaje durante gran parte del siglo XIII y el siglo XIV. ${ }^{55}$ Nuevos hallazgos documentales en el Archivo de la Corona de Aragón nos han permitido, sin embargo, comprobar que la relación entre este viejo linaje noble y el monasterio cisterciense continuó siendo muy estrecha hasta que se produjo la extinción biológica del mismo en la segunda década del siglo XIV.

Estos hallazgos nos informan en particular sobre la figura de Ruy Díaz de Finojosa, el último representante del linaje en aquella comarca castellana fronteriza con Aragón. No hemos conseguido averiguar mucho acerca de él, aunque sí lo suficiente como para concluir que fue un destacado señor de vasallos, que estuvo muy vinculado en vida con la comunidad de Huerta. Así nos lo confirma en concreto su movilización ante el rey de Aragón Jaime II en el año 1311 para que se hiciese justicia en el oscuro caso de la muerte violenta de un monje llamado fray Cristóbal, que había tenido lugar en territorio aragonés. ${ }^{56}$ Del contenido de la carta que el monarca aragonés le envió con motivo de aquel suceso a Ruy Díaz de Finojosa se deduce que fueron los vecinos de Monreal de Ariza los responsables de la muerte del monje, que es bastante probable que tuviese lugar en el transcurso de algún altercado violento suscitado

51 AHN, Códice 1295b. La hacienda que el monasterio tenía en Cuenca y su comarca costó la sangre a muchos y nobles caballeros que están enterrados en el monasterio. Dicha hacienda era «tanta y tan preciosa que se podía mantener a satisfacción un monasterio de 24 monjes», y según Manrique le valía al monasterio en otro tiempo más de 4.000 ducados anuales. Entre los bienes donados por Nuño Sancho en este códice se mencionan 16 casas y un mesón en Calle de la Moneda en Cuenca, en 1177, y el término de Albaladejo del Cuende en 1202. Más informaciones de interés sobre estas donaciones de propiedades en Cuenca en García Luján 1981.

52 Romero Redondo 1962: 93-116.

53 Fernández Martín 1963: 159-181.

54 Da noticia detallada de las donaciones de términos que San Martín de Finojosa y su familia efectuaron al monasterio de Santa María de Huerta, Ávila Seoane 2009.

55 Moxó destaca los nombres de Martín Muñoz de Finojosa, que tomó parte en la batalla de Las Navas de Tolosa, y sus descendientes Diego Martínez y Juan Díez de Finojosa, que aparecen en la documentación relativa a la conquista y colonización de Andalucía.

56 ACA, C, reg. 240-20-137v, Calatayud, 20-I-1313. Carta de Jaime II a Ruy Díaz de Finojosa. por diferencias sobre aprovechamiento de términos, en el que estuviesen también implicados los vecinos de Torrehermosa, vasallos del monasterio. En cualquier caso, al margen de las circunstancias concretas en que se produjese la muerte del monje, lo que nos interesa destacar aquí es que Ruy Díaz de Finojosa intervino en persona, sustituyendo al propio abad de Huerta, ante el rey de Aragón para que se hiciese justicia. Además, no se limitó a presentar un mero ruego, sino que aparentemente amenazó también con acciones violentas de represalia en caso de no obtener respuesta satisfactoria. Así lo sugiere el hecho de que el rey de Aragón en su carta le advirtiese explícitamente que, dado que el caso del homicidio había sido investigado conforme a las disposiciones de los fueros, no tendría justificación que emprendiese ninguna acción que causase daño a los vecinos de Monreal, pues ya se había impartido justicia. ${ }^{57}$

No disponemos de más noticias sobre actuaciones en la vida política de esta comarca de frontera de Ruy Díaz de Finojosa en los años que siguieron al restablecimiento de la paz entre Castilla y Aragón en 1304. Pero resulta de interés destacar que, tras su muerte hacia 1319, el abad del monasterio de Huerta fue su albacea testamentario. $\mathrm{Y}$, como tal, se encargó de negociar la venta de uno de sus señoríos, la villa de Velamazán, en una compleja operación en la que se implicó el propio monarca aragonés, Jaime II, que en nombre de su hija María, y de su nieta Blanca, llegó a ponerse en contacto directamente con el abad de Huerta, dirigiéndole una carta en septiembre de 1319, en la que trató sobre el asunto de la venta de esta villa ubicada en la comarca soriana, entre Almazán y Berlanga. ${ }^{58}$ Le agradecía en dicha misiva por haber accedido a reunirse con su hija la infanta María, viuda del infante castellano Don Pedro, para tratar del referido negocio. Le había prometido en la entrevista a la infanta que la tendría avisada de las gestiones que como manumisor del difunto Ruy Díaz de Finojosa realizase para la venta de Velamazán, a fin de que ella pudiese adquirir el lugar para su hija Blanca antes que ningún otro potencial comprador. Y efectivamente, aunque tras muchas vacilaciones, la villa terminó siendo adquirida para engrosar el compacto bloque de señoríos que a Doña Blanca correspondió heredar de su padre, el infante Don Pedro. ${ }^{59}$

Estas informaciones sobre la operación de venta de Velamazán nos confirman la estrecha vinculación que se había dado entre Ruy Díaz de Finojosa y la comunidad cisterciense de Huerta, aunque lamentablemente resultan en exceso lacónicas para reconstruir con algo más de detalle el perfil sociopolítico de este caballero. En cualquier caso, para reforzar la tesis sobre la vinculación mantenida por este último vástago del ilustre linaje de los Finojosa con el monasterio cisterciense en que se habían enterrado sus gloriosos antecesores de la segunda mitad del siglo XII y comienzos del siglo XIII, traeremos a colación una noticia que proporciona fray Salvador Parracía y Moure en su manuscrito de 1801. Anota, en efecto, que en 1331 Ruy Díaz de Finojosa, deudo de San Martín, hizo donación a Santa

57 En términos literales el monarca le recordaba: «...nos haríais tuerto y desaguisado si por esta razón causaseis algún daño a nuestros hombres de Monreal».

58 ACA, C, reg. 245-185, Tarragona, 26-IX-1319.

59 Diago Hernando 2005: 47-90. 
María de Huerta para después de sus días de ocho yuntas de heredad que tenía en Taroda. En caso de tratarse del mismo personaje que fue señor de Velamazán, no hay duda de que la fecha de 1331 debe estar equivocada. Pero, por lo demás, sí resulta verosímil que en fecha anterior tal donación se realizase efectivamente.

\section{EL MONASTERIO DE HUERTA BAJO LA INFLUENCIA DE LOS DUQUES DE MEDINACELI (SIGLOS XV-XVII)}

Ruy Díaz de Finojosa fue el último representante de la vieja nobleza en tierras sorianas. Hubo que esperar al acceso al trono castellano de la dinastía Trastamara para que en las últimas décadas del siglo XIV se iniciase el proceso de arraigo de la nueva nobleza de la que habló Moxó, que pasó a dominar el escenario político regional hasta el fin del Antiguo Régimen. Uno de los principales representantes de esta nueva nobleza en la región soriana fue el linaje de los Bearne-De La Cerda, que desde su base de Medinaceli terminó ejerciendo un dominio indiscutido en todo el territorio fronterizo con Aragón donde se ubicaba el monasterio de Santa María de Huerta. Como consecuencia éste no tardó en quedar sometido a una relación de clara dependencia respecto a dicho linaje, no exenta de puntuales tensiones. ${ }^{60}$

Huerta no dejó en ningún momento de jactarse de ser un monasterio de Real Patronato. Pero lo cierto que desde el final de la Edad Media la atención que le prestaron los monarcas castellanos fue en franco retroceso, mientras que por contraste se incrementaba la prestada por los condes, y luego duques, de Medinaceli. Desde el primer momento en que este linaje hizo su aparición en tierras sorianas, gracias a la obtención del señorío jurisdiccional sobre la villa de Medinaceli y su extensa Tierra por merced de Enrique Il al caballero de origen francés Beltrán de Bearne, casado con Isabel de la Cerda, fueron muy estrechas las relaciones que sus miembros establecieron con Huerta. Así, tanto el propio Beltrán de Bearne como su esposa quisieron que sus cuerpos fuesen enterrados en la iglesia del monasterio, y su ejemplo fue seguido por sus sucesores de varias generaciones, en concreto el segundo conde de Medinaceli, Gastón de la Cerda, el tercer conde, Luis de la Cerda, que otorgó testamento en 1447, y la esposa de éste, la condesa Juana Sarmiento, que había testado en $1435 .{ }^{61}$

La elección del monasterio como lugar de enterramiento tuvo como contrapartida la concesión de generosas mercedes al mismo, con frecuencia a cambio de la exigencia de la celebración de misas y sufragios. Así, el conde Luis de la Cerda, tras la muerte de su esposa, Juana Sarmiento, en febrero de $1435^{62}$ dispuso que en adelante el abad y monjes

60 Sobre la cuestión del patronato aristocrático en monasterios cistercienses castellanos, aunque se centra exclusivamente en el caso de los femeninos, y no presta atención al período bajomedieval, interesa Baury 2012.

61 Información al respecto en los testamentos que publica Pardo Rodríguez 1993.

62 Pardo Rodríguez 1993: doc. no. 167. Testamento que otorga el conde Luis de la Cerda en nombre de su difunta esposa, Juana Sarmiento, en Medinaceli, 25-II-1435. Vid. también en doc. no. 169 la aceptación de compromiso para cantar las capellanías por el abad y monjes en 6-II-1436. de Huerta cantasen cuatro capellanías perpetuas de cuatro misas diarias, una por el alma de la difunta condesa, otra por la suya propia, otra por la de su padre, el conde Gastón, y otra por las de los condes Beltrán de Bearne e Isabel de la Cerda, sus abuelos. A cambio el titular del mayorazgo quedaba obligado a perpetuidad a pagar cada año a los monjes 5.000 mrs. para vestuario y calzado, situados sobre la martiniega de las aldeas de la Tierra de Medinaceli, y sobre un molino y batán con otras propiedades ubicadas en Mandayona, antigua aldea de Atienza. Además dispuso que se cantasen en el monasterio otras 300 misas por las ánimas de los padres de Juana Sarmiento. Por supuesto, además de en Huerta, el conde también ordenó la celebración de oficios litúrgicos en otros muchos establecimientos eclesiásticos, ubicados en su mayoría en sus señoríos castellanos o andaluces. Pero un claro indicio de que este monasterio cisterciense era en aquellos momentos el que gozaba de su mayor estima lo encontramos en el hecho de que fue sistemáticamente favorecido frente a los demás por la cuantía de las mercedes que le hizo. Así, a la hora de disponer que se cantasen treintenarios, marca una clara diferencia entre Huerta, ordenando que allí se celebren dos, frente a los monasterios de Piedra, Santa Clara de Tordesillas y San Benito de Valladolid, y las iglesias de Santa María de Medinaceli, Santa María del Puerto y Santa María de la Val, donde ordenó que sólo se celebrase uno. Por su parte, al fijar la cuantía de las mercedes en dinero destinadas a ayuda a la financiación de las obras de mantenimiento de los edificios religiosos, estableció una clara diferencia entre el monasterio de Huerta, al que señaló 3.000 mrs. y los demás, que sólo recibieron 1.000 mrs. o cantidades inferiores. ${ }^{63}$ Años después de la muerte de su esposa, el propio conde Luis, en su testamento de 1447 , volvió a mostrarse especialmente generoso con los cistercienses de Huerta, al ordenar que se les abonasen 10.000 mrs. por acoger su cuerpo en el interior de la iglesia monástica, junto al de sus antepasados, y que se le dijesen tres treintenarios de requiem. Además, dejó constancia de que había encargado realizar a su costa un retablo para dicha iglesia, que todavía no se había finalizado, por lo que encargó a sus albaceas que se acabase y se procediese a continuación a su colocación. Y por fin, también ordenó que las salinas del monasterio, que estaban localizadas cerca de la villa de Medinaceli, le fuesen dejadas a éste «libre y desembargadamente», lo que sugiere que quizás en vida él mismo había estado usurpando su aprovechamiento a los monjes. ${ }^{64}$

En efecto, la relación que los señores de Medinaceli del linaje Bearne-De La Cerda establecieron con la comunidad monástica de Huerta fue bastante compleja y estuvo marcada por el signo de la duplicidad y la contradicción. Por un lado existen pruebas inequívocas de la generosidad de estos poderosos nobles hacia los monjes cistercienses. Pero, por otro lado, también abundan los indicios de que se esforzaron por colocarlos bajo su férreo control, a ellos y a sus vasallos, no absteniéndose de agredirles y usurparles sus propiedades, mediante el crudo uso de la fuerza, cuando lo estimaron necesario para la consecución de sus fines.

63 Para la obra de Guadalupe donó 600 mrs., para la de Santa María de Sigüenza 1.000 mrs., para la de Santa María de Medinaceli 1.000 mrs., para la de Santa María Magdalena 300 mrs. y para la de Santa María del Puerto 1.000 mrs.

64 Pardo Rodríguez 1993: doc. no. 200. Medinaceli, 6-VIII-1447. 
Es en el transcurso de la primera mitad del siglo XV cuando comenzamos a encontrar en la documentación indicios más contundentes de la intensificación de la influencia ejercida por los condes de Medinaceli sobre el monasterio, que era la institución eclesiástica de mayor prestigio en el ámbito regional donde ejercían su dominio. Resultan muy ilustrativas desde esta perspectiva las cartas que dirigió al conde la reina María, gobernadora de Aragón en ausencia de su marido, en 1441. Fue con ocasión del enfrentamiento que la comunidad cisterciense mantuvo con la villa y aldeas de Ariza al que ya nos hemos referido. La reina, efectivamente, apeló entonces de forma directa al conde, atribuyéndole la última responsabilidad de las actuaciones del abad y convento de Huerta, en los siguientes términos: sabemos y creemos que dicho abad no osaría hacer sino lo que vos le mandaseis, pues sin scalfo vuestro él sería muy poco para hacer lo que amenaza. ${ }^{65}$

Por otro lado, también apunta en el mismo sentido otra carta de junio de 1444, en la que la reina recrimina al conde por haber puesto por su propia autoridad un alcaide en Torrehermosa, población aragonesa perteneciente al monasterio de Huerta, desde donde amenazaba a los vecinos de Ariza. ${ }^{66} \mathrm{Al}$ haber puesto un alcaide en un lugar del monasterio, el conde demostraba abiertamente que tenía sometido a éste a su plena autoridad, hasta el punto de hacer uso de su patrimonio como si fuese suyo propio. Era una forma de proceder idéntica a la de otros muchos nobles castellanos, leoneses y gallegos que impusieron encomiendas forzosas sobre muy diversos monasterios, en su mayoría benedictinos aunque también cistercienses, durante el período bajomedieval. ${ }^{67}$

Por otro lado, nos consta que con posterioridad, en el contexto de los enfrentamientos con Aragón, los condes de Medinaceli utilizaron Huerta como base para sus operaciones militares, como si de un lugar más de sus dominios se tratase. Así nos lo confirma, por ejemplo, una anotación encontrada en una relación de gastos del concejo aragonés de Ateca, próximo a la frontera, en el año 1467, referente al pago efectuado por el cogedor a un correo de Buvierca "que trayo avis como gente del conde estava en Huerta». ${ }^{68}$

El fin de los conflictos fronterizos tras la consolidación en los tronos de Castilla y Aragón de los Reyes Católicos, no restó protagonismo en el escenario político regional a los señores de Medinaceli, elevados a la condición de duques por los nuevos monarcas. Más bien al contrario les facilitó la consolidación de su posición como la principal instancia de poder de la región, por debajo de los reyes, con los que mantuvieron una relación exenta de reseñables tensiones. Como consecuencia pudieron continuar ejerciendo una estrecha y rigurosa tutela sobre Huerta, como nos lo demuestran unos interesantes documentos del año 1480.

65 ACA, C, reg. 3180-81v, Alcañiz, 1-VI-1441.

66 ACA, C, reg. 3190-96v, Valencia, 26-VI-1444.

67 Sobre la utilización abusiva de la institución de la encomienda en el siglo XIV vid. Santos Díez 1949. Sobre la persistencia de la práctica en los siglos XV y XVI se proporcionan ejemplos en Diago Hernando 1992: 811-61 e ídem 2014: 359-388.

68 Rubio Semper 2006: 261. Poco antes, en este mismo año el cogedor había pagado a un correo que vino de Moros, «sobre la cabalgada que hizo el conde en Bijuesca» (página 256).
Se refieren al conflicto que en ese año se planteó en torno a la localización de las aduanas entre los reinos de Castilla y Aragón, y el pago de derechos aduaneros por las gentes del monasterio. Pero, dejando a un lado el análisis en detalle de la problemática planteada, lo que aquí interesa resaltar es que, a la hora de defender en esta ocasión sus intereses, la comunidad monástica dirigió un elevado número de cartas al duque de Medinaceli, en las que explícitamente le reconoció "que otro señor no tenemos». ${ }^{69}$

Por supuesto, de esta situación de dependencia no dejaron de derivarse tensiones, que al menos en una ocasión dieron lugar al estallido de graves episodios de violencia. En efecto, en los últimos años del siglo XV surgieron graves diferencias entre los duques de Medinaceli, y sus vasallos vecinos de la villa y las aldeas del ducado, de un lado, y los monjes de Huerta, y sus vasallos y renteros que trabajaban sus tierras, de otro. Estas diferencias alimentaron el desarrollo de tensiones, que amenazaban con desembocar en acciones violentas. Lo pone de manifiesto la solicitud presentada en 1494 en nombre del monasterio por un individuo llamado Lope de Sebastián, quien requirió a los reyes ante el Consejo Real que concediesen a sus partes carta de seguro que les pusiese a salvo de previsibles ataques del duque de Medinaceli y miembros de su clientela, de quienes se recelaban porque habían tratado negocios en defensa de los intereses del monasterio que afectaban al duque. ${ }^{70}$ Aunque la carta de seguro no aclara de qué negocios se trataba, debían guardar relación con la delimitación de los términos que eran propiedad de cada parte, y la fijación del régimen de aprovechamiento de los mismos. Tenemos constancia, en efecto, de que el monasterio llegó a denunciar ante los monarcas que el duque y sus vasallos le tenían ocupados ciertos términos que eran de su propiedad. Y en respuesta a esta denuncia los Reyes Católicos comisionaron en 1499 al bachiller Juan de Molina para que se los restituyese. ${ }^{71}$ Este juez, después de haber tomado información, dictó una sentencia ese mismo año por la que fijó los límites de los términos que eran propiedad del monasterio con respecto a los que pertenecían a los lugares del ducado de Medinaceli, remitiéndose para ello a lo dispuesto en el privilegio del rey Alfonso VIII de concesión de términos a Huerta. Aunque esta sentencia no se conserva en su versión original se hace referencia a ella en documentos posteriores, en que es confirmada, y más en concreto en la sentencia arbitral pronunciada por el doctor Ignacio Collantes en la villa de Medinaceli el 18 de julio de $1504 .^{72}$ En este último documento se hace constar explícitamente que el motivo principal del descontento del monasterio radicaba en que desde hacía aproximadamente un cuarto de siglo, los guardas del duque por su mandado y de la villa de Medinaceli, y otros vecinos del ducado, por fuerza y contra la voluntad del abad y monjes, habían entrado con armas para tomar la mayor parte de los términos contenidos en el

\footnotetext{
69 Pérez-Embid 1986: 343.

70 AGS, RGS, XI-1494, fol. 223. Es carta de seguro dirigida a las justicias de las villas de Medinaceli, Monteagudo y Almazán.

71 Noticia sobre el envío del bachiller Juan de Molina como juez comisionado para devolver los términos tomados, en AGS, RGS, III-1504. Comisión al bachiller Gonzalo de Grijera.

72 Esta sentencia arbitral se puede consultar en AHPS, Hacienda, Caja 4986, doc. 22-17.
} 
privilegio de Alfonso VIII, prendando en ellos a los vasallos y renteros del monasterio, y procediendo a su roturación.

La actuación del bachiller Juan de Molina como juez de términos no logró acabar con las tensiones, sino que por el contrario se recrudecieron aún más tras su partida, para terminar estallando en sucesivos episodios de violencia en el transcurso del año 1504. Así, en primer lugar, según denuncia que presentó en la Corte el abad de Huerta, fray Sebastián de Campuzano, en un día del mes de febrero de ese año, uno de los miembros más importantes de la clientela del duque de Medinaceli, el alcaide de su fortaleza de Montuenga, Pedro de Uceda, irrumpió al frente de un grupo de personas armadas en los términos del monasterio, procediendo a descepar una viña y apresar a unos criados suyos, llevándose finalmente consigo seis pares de bueyes y mulas, y otros ganados. ${ }^{73}$ Más adelante, según documento de la Cámara de Castilla que cita Pérez Embid, tuvo lugar un ataque por las gentes del duque a los vasallos del monasterio en su lugar de Torrehermosa, en el reino de Aragón, a donde habrían acudido armados 30 caballeros y 300 peones, que mataron al único individuo que encontraron, pues las mujeres del pueblo se habían refugiado en la iglesia y los hombres habían huido al monte. ${ }^{74}$ Por fin, la escalada de violencia culminó poco después con el cerco del monasterio, el quebrantamiento de su granero, la destrucción de colmenas y el robo de gran cantidad de cereal, que finalmente se estimó en torno a las 300 fanegas.

Al carácter sacrílego de las actuaciones de los vasallos del duque de Medinaceli en este ataque a los edificios del monasterio de Huerta, se añadió además un factor de desobediencia a la autoridad regia. En efecto, los reyes habían comisionado a un juez pesquisidor, el bachiller Grijera, para que averiguase e hiciese justicia sobre lo ocurrido, pero cuando éste iba a proceder a arrestar a Rodrigo de la Serna, alcalde de Medinaceli al que había encontrado culpable de la comisión de delito, otros varios vecinos de esta villa ofrecieron resistencia armada para impedirle que lo prendiese. No pudo por ello cumplir la misión que le habían encomendado los reyes, y como consecuencia éstos tuvieron que comisionar acto seguido a un nuevo juez pesquisidor, Martín Vázquez de Rojas, para que se trasladase a Medinaceli. ${ }^{75}$

Llama la atención, sin embargo, que a pesar de la gravedad de todos estos sucesos del año 1504, ocurridos en menosprecio del carácter sagrado de los edificios monásticos y de las personas de los monjes, y en abierta desobediencia a los oficiales del rey, se saldaron sin que ni el duque de Medinaceli ni sus vasallos sufriesen un duro castigo. Se buscó, en efecto, una solución conciliatoria, dejando en manos de un juez árbitro, el doctor Ignacio Collantes, administrador perpetuo del monasterio de Santa María de Óvila y visitador general del obispado de Sigüenza, la resolución del conflicto. En la sentencia arbitral que éste pronunció ${ }^{76}$, ordenó que

\footnotetext{
73 AGS, RGS, III-1504. Comisión al bachiller Gonzalo de Grijera.

74 Pérez-Embid 1986: 645. Remite a un documento de AGS, Cámara-Pueblos, leg. 17.

75 AGS, RGS, VI-1504. Comisión a Martín Vázquez de Rojas, vasallo de los reyes.

76 El tenor de la sentencia, pronunciada en el portal de la iglesia de San Juan del Baño, de Medinaceli, el 18-VII-1504, en AHPS, Hacienda, Caja 4986, doc. 22-17.
}

se indemnizase al monasterio por el valor del cereal que había perdido y por los destrozos realizados en puertas y cerraduras. Pero la pena más significativa que impuso a los vasallos del duque a los que encontró culpables se resumió en obligarles a realizar, con anterioridad al día de Santa Lucía de ese mismo año, un acto simbólico de penitencia. En concreto, en representación de todos los que habían participado en la comisión del delito, habrían de acudir al monasterio los once principales oficiales de la villa y Tierra - dos alcaldes, cuatro regidores, dos diputados, un procurador, un regidor de la villa y escribano del Común del ducado, y un escribano del número de la villa - junto con otros vecinos que ellos escogiesen, hasta sumar un total de veinte personas. Todos ellos deberían participar en una procesión que se iniciaría en un punto fuera de la puerta del monasterio, identificado por la presencia de un olmo. La forma en que debían ir ataviados quedó fijada en los siguientes términos: en cuerpo en jubones y con los sayos de la cinta arriba caídos sobre la cintura, y descalzos de pies y piernas, descubiertas las cabezas, con sendas gruesas sogas ceñidas sobre el dicho medio sayo caído, y con sendos cirios de cera en las manos. De esta guisa deberían avanzar hasta la segunda puerta del monasterio, que había sido rajada y quebrantada por el alcalde Rodrigo de la Serna, y allí, a la entrada del portal, saldría a recibirlos el abad, para proceder a absolverlos. A fin de obtener la absolución deberían todos ellos hincarse de rodillas $y$, en su propio nombre y en el de todos los demás cómplices y partícipes, humildemente pedir perdón por amor de Dios al abad y convento de todas las culpas y ofensas que en sus personas, casa y bienes hicieron, y absolución de las censuras y penas eclesiásticas en que por ello incurrieron. El abad debería entonces perdonarlos y restituirles a los sacramentos. Después de recibida la absolución, los penitentes procederían a encender los cirios y entrar en procesión en la iglesia para asistir a la misa, permaneciendo en pie durante la misma. Y después de acabada ésta deberían ofrecer en el altar los cirios y antorchas, con sendos reales en cada cirio, pudiendo marchar a continuación «con Dios en paz».

Al margen de esta penitencia, el juez árbitro no quiso imponer ninguna otra condena ni contra los vasallos ni contra el duque, a la vez que absolvió explícitamente a éste de cualesquier costas, gastos, daños e intereses a que fuese obligado. Justificó su clemente forma de proceder en los siguientes términos:

Lo cual hacemos por bien de paz y concordia, y servicio y acatamiento de su señoría, y de la señora duquesa, porque esperamos que en mucho más que aquello podía montar, sus muy ilustres y magníficas señorías se recordarán de hacer otras mayores mercedes al dicho monasterio, y servicio de Nuestra Señora, y descargarán sus conciencias, si en algo cerca de lo susodicho se hallaren ante Dios y su gloriosa madre culpadas, cuyas ánimas y claras conciencias en esta parte mucho encargamos.

Era una forma de reconocer que el monasterio se encontraba en una situación de manifiesta dependencia respecto al duque, y que le resultaba más conveniente acogerse a su magnanimidad que verse arrastrado a una relación de enfrentamiento, en la que tenía las de perder, por su mayor debilidad relativa. En cualquier caso, al margen de estos violentos sucesos del año 1504, que de forma 
tan favorable para la posición del duque de Medinaceli se resolvieron, algunos otros indicios nos confirman que durante el reinado de los Reyes Católicos éste había logrado auparse a una posición de indiscutida preeminencia en su relación con el monasterio de Huerta. De hecho se trataba de una posición que guardaba muchos parecidos con la tutela que otros nobles ejercían por aquellas fechas sobre otras comunidades monásticas del reino de Castilla de las que se autoproclamaban encomenderos.

Entre dichos indicios destacaríamos los relativos al papel desempeñado por el duque en el proceso de introducción de la reforma observante en Huerta. Ciertamente se trata de un proceso no bien conocido en todos sus detalles, que se prolongó de forma extraordinaria en el tiempo, y no presentó un carácter lineal, sino que experimentó notorios altibajos. El monasterio de Huerta fue uno de los pioneros en el proceso de incorporación a la Congregación observante del Císter en la Corona de Castilla, pues ya hay constancia de su unión parcial al movimiento en el año 1469, aunque este primer intento finalmente no prosperó. ${ }^{77}$ Hubo que esperar al reinado de los Reyes Católicos para que en 1496 éstos encargasen al obispo de Catania de su reforma, tras haber obtenido para ello bula del papa. A fin de facilitar a éste el cumplimiento de su misión, dirigieron provisión a los oficiales de la justicia para que le prestasen favor y ayuda, cumpliendo todos sus mandamientos. ${ }^{78}$ La voluntad de los reyes fue acatada, y el monasterio fue puesto "en observancia», siendo designado como su primer abad trienal fray Sebastián de Padilla. ${ }^{79}$ Pero muy poco tiempo después, una provisión real del año 1500, nos informa que, encontrándose dentro del monasterio el nuevo abad y los monjes bajo seguro y amparo real, en una noche del mes de octubre de ese año varios frailes claustrales, acompañados de diversos laicos, todos ellos armados, habían atacado el edificio y se habían apoderado de él por la fuerza, rompiendo paredes, y encerrando en una mazmorra a los frailes observantes. ${ }^{80}$

La identificación de los laicos que colaboraron con los frailes claustrales en el ataque y toma del monasterio no resulta fácil. A partir de la misma no se puede por tanto concluir que el duque de Medinaceli hubiese apoyado esta acción violenta en contra de la reforma. Pero proporciona al menos algún indicio que apunta en este sentido, pues entre los asaltantes hubo vasallos suyos, como García de Torres, hijo de Rodrigo de Torres, o Miguel Sánchez, molinero de Montuenga. No obstante, está fuera de duda que el principal urdidor de este intento violento de revertir el proceso de implantación de la reforma observante en Huerta fue el último abad perpetuo del monasterio, Álvaro de León.

La reina, no obstante, reaccionó de inmediato, comisionando a un juez pesquisidor, el contino Carlos Osorio, para que se desplazase a desencastillar el monasterio, ordenando a todos los oficiales de la justicia que le prestasen ayuda para llevar a efecto su misión con éxito. ${ }^{81}$ Pocos meses después, en abril de 1501, decidió

\footnotetext{
77 Martín 1953: 28; Pérez-Embid 1986: 673.

78 AGS, RGS, V-1496, fol. 149.

79 Pérez-Embid 1986: 673.

80 AGS, RGS, XI-1500, fol. 174. Comisión a Carlos Osorio, contino.

81 AGS, RGS, XI-1500, fol. 408. Provisión dirigida a los oficiales de la justicia de todas las ciudades.
}

encargar al arzobispo de Toledo, el cardenal Cisneros, que llevase adelante la empresa de la introducción de la reforma observante en Huerta y en el priorato de San Bernardo de Sevilla, habida cuenta que en ambos casos el recurso a la violencia de quienes se oponían a dicha reforma había impedido su consolidación. ${ }^{82}$

Para facilitarle su misión no dudó en esta ocasión en recurrir a dos poderosos miembros de la alta nobleza, el duque de Medinaceli y el duque de Nájera, enviándoles sendas cédulas para que prestasen favor y ayuda en todo lo que Cisneros les solicitase a fin de que el monasterio de Huerta fuese restituido cuanto antes a la práctica de la regular observancia. ${ }^{83} \mathrm{El}$ que recurriese al duque de Medinaceli resulta lógico, pues sus señoríos castellanos se ubicaban en la inmediata proximidad del monasterio y él representaba la principal "potencia militar» de aquella comarca. Por el contrario los señoríos del duque de Nájera se encontraban bastante más alejados, localizándose los más cercanos en Cameros y Rioja, habida cuenta que, aunque en 1497 el mariscal Carlos de Arellano intentó venderle el señorío de su villa de Ciria, próxima a Huerta, los reyes no autorizaron la operación. Por ello resulta más difícil comprender las razones que pudieron mover a la reina a recurrir a él en demanda de colaboración, aunque tampoco tenemos noticias de que llegase a implicarse en la empresa.

Por lo que respecta a la actitud que entonces mostró el duque de Medinaceli tampoco estamos bien informados. Pero es seguro que antes de que se produjese la muerte de la reina Isabel la observancia ya había sido restablecida en Huerta. Lo atestigua la documentación del año 1504 relativa al conflicto surgido con motivo del ataque al monasterio perpetrado por los oficiales y vecinos del ducado de Medinaceli, en la que se reproduce la licencia que había otorgado a los monjes de Huerta fray Pacífico de Liaño, abad reformador y superior de todos los monasterios del Císter de la Observancia, para que pudiesen comprometer la resolución de sus diferencias con el duque y sus vasallos en el doctor Ignacio Collantes como juez árbitro.

En documentación de fecha posterior encontramos, sin embargo, indicios que llevan a sospechar que las resistencias a la reforma no quedaron totalmente erradicadas, y resurgieron en momentos de inestabilidad política como los que se vivieron en las vísperas del estallido de la revuelta comunera. Así, en 1520, habiéndose desplazado un reformador de la Orden del Císter a visitar Huerta, uno de los caballeros principales de la clientela del duque de Medinaceli, el alcaide de la fortaleza de Montuenga, le impidió por la fuerza que realizase la visita, para lo cual llegó a encastillar el edificio monástico. ${ }^{84}$ Esta noticia sugiere que la sombra de la casa de Medinaceli seguía proyectándose sobre la vida interna de esta comunidad cisterciense, tomando partido en los conflictos que en el seno de la misma se venían planteando desde hacía mucho tiempo entre defensores y opositores de la observancia. Sería deseable, no obstante, ampliar nuestra información con

82 AGS, Cámara-Cédulas, 5, 125, 2. Granada, 18-IV-1501. Cédula al arzobispo de Toledo.

83 AGS, Cámara-Cédulas, 5, 125,4. Granada, 18-IV-1501. Cédula al duque de Medinaceli, y 8, 39, 2. Granada, 3-III-1501. Cédula al duque de Nájera, Pedro Manrique.

84 AGS, RGS, VI-1520. 
otras noticias que nos permitiesen conocer con algo más de detalle el papel que los duques desempeñaron en este conflicto, que, por lo dicho, parece que no fue irrelevante.

La incorporación definitiva de Huerta a la Congregación observante no supuso, sin embargo, un freno para al proceso de reforzamiento de la influencia ejercida por la casa de Medinaceli sobre esta comunidad cisterciense. Es cierto que el primer duque rompió con la tradición de sus antepasados de enterrarse en este monasterio, pues inicialmente eligió como lugar de enterramiento el monasterio jerónimo de Lupiana, aunque a los pocos días cambió de opinión, ordenando que sus restos mortales reposasen en la iglesia de Santa María de su villa de Medinaceli. Pero de nuevo su sucesor, el segundo duque, Juan, volvió a elegirlo como definitivo lugar de reposo de sus restos mortales, compensando a la comunidad cisterciense con generosas donaciones, de entre las que cabe destacar un dosel de brocado para que se colocase sobre su tumba, un dosel de terciopelo negro para los días de diario, y la limosna correspondiente a 1.500 misas que dispuso que se rezasen por su alma en la iglesia monástica, de un total de 5.000 que encargó en su testamento del año $1544 .{ }^{85}$

Esta generosidad iba aparejada con un evidente incremento de la presión, que los duques no dudaron en ejercer en perjuicio incluso del propio monasterio, movidos por el afán de hacer prevalecer sus intereses particulares. Buen ejemplo de ello lo tenemos en el intento que el cuarto duque de Medinaceli, Juan de la Cerda, protagonizó en el año 1553 de anexionar a sus dominios jurisdiccionales del ducado el enclave del barrio de Huerta, constituido por las viviendas de los renteros del monasterio, construidas en torno a éste. Desconocemos en detalle los argumentos con que pudo tratar de justificar tal operación, pues de lo único de lo que tenemos constancia es de que el monasterio se opuso con éxito a la misma, argumentando que el barrio no constituía un concejo propiamente dicho, dado que allí sólo residían renteros. ${ }^{86}$ Quizás el duque ofreció a la Monarquía algún dinero a cambio de que le cediese la jurisdicción sobre dicho barrio, y de ahí la reacción del monasterio. Pero, en cualquier caso, lo que aquí nos importa destacar es que el duque no vaciló a la hora de intentar arrebatar a Huerta un elemento emblemático de su patrimonio, como era el de la jurisdicción sobre sus propios renteros y en última instancia sobre todo el término que rodeaba al monasterio, dejándole únicamente la propiedad dominical.

Esta doblez en la actitud de la casa de Medinaceli hacia el monasterio de Huerta siguió presidiendo las relaciones entre ambas partes a lo largo de todo el período moderno, durante el que se mantuvo inquebrantable la situación de dependencia de la comunidad monástica respecto a la casa ducal, no sin que de vez en cuando la primera realizase alguna manifestación formal de protesta, a fin de lograr al menos alguna contraprestación. Es lo que ocurrió a comienzos del reinado de Felipe IV, cuando los monjes se negaron a reconocer formalmente las pretensiones de los duques de Medinaceli de que se les reconociese como derecho

85 Copia del testamento del segundo duque de Medinaceli, otorgado en Cogolludo, 18-I-1544, en AChV, P. C. Alonso Rodríguez, Depositados, C. 120-1.

${ }^{86}$ Informa al respecto, basándose en un documento del Tumbo de Huerta, manuscrito del siglo XVII, Romero Redondo 1976: 60. adquirido el poder ser enterrados en la capilla mayor del monasterio. Era un hecho que muchos miembros relevantes de la casa ducal en el transcurso de las generaciones habían recibido sepultura en aquella capilla. Pero la comunidad cisterciense puso buen ciudado en recalcar que se les había admitido por voluntad de los monjes, y no porque los miembros de la casa ducal poseyesen un derecho a ser allí enterrados. Como consecuencia se inició pleito ante el ordinario eclesiástico del obispado de Sigüenza, pero, antes de haberse resuelto el mismo, ambas partes accedieron a llegar a un acuerdo amistoso. Éste fue firmado en Medinaceli el 27 de julio de 1633, y poco después confirmado por el rey Felipe IV por provisión de 28 de noviembre de ese mismo año. ${ }^{87}$ En virtud del mismo el monasterio cedió a las principales pretensiones del duque, pero a cambio consiguió una importante contraprestación económica, consistente en el pago a partir de entonces de una renta anual de 500 ducados a perpetuidad. Más en concreto el duque logró que el monasterio le reconociese para sí y sus sucesores en el mayorazgo el derecho "negativo» de enterramiento en la capilla mayor de la iglesia monástica, que hasta entonces no había tenido, como lo demostraba la presencia de otros cuerpos enterrados que no habían pertenecido a la casa ducal. Es decir, que para el futuro los duques se aseguraban que sólo ellos podrían continuar siendo enterrados en la referida capilla, y nadie más, aunque dicho derecho quedaba restringido a los mayorazgos que llegasen a ostentar el título ducal, quedando excluidos los demás miembros "segundones» del linaje. También se les reconoció el derecho de poder «ilustrar» sus sepulcros en la forma que mejor les pareciere, sin detrimento de las sepulturas de los cuerpos santos que estaban en la capilla, ni del patronato real de la misma. Del mismo modo se dispuso que las armas reales que había en la capilla nunca pudiesen ser quitadas, pero al mismo tiempo se autorizó al duque a poder poner sus armas en todo lo nuevo que edificase en ella. El monasterio, además, se aseguró que con ocasión de la celebración de cada enterramiento de duque o duquesa se le abonasen los derechos acostumbrados, que eran en concreto los machos de la litera que llevase el cuerpo y el paño con que fuese cubierto. Y a cambio quedó comprometido a celebrar todos los años, el primer día ferial después de la fiesta de las Ánimas, un oficio solemne de difuntos por los señores de la casa de Medinaceli, «con su invitatorio, vigilia y misa de pontifical», y responso en la capilla mayor, debiendo por ello recibir como ofrenda 40 fanegas de trigo, 40 cántaras de vino y 4 carneros.

De este modo, sin que la condición de monasterio de patronato real de Santa María de Huerta fuese puesta en cuestión, los duques de Medinaceli consiguieron hacerse reconocer una posición de preeminencia en sus relaciones con esta casa que equivalía de facto al patronato. En efecto, gracias al acuerdo corroborado por el rey en 1633, en adelante sólo los mayorazgos de la casa de Medinaceli tendrían reconocido el derecho a ser enterrados y colocar sus armas en la capilla mayor del monasterio, compartiendo espacio con prestigiosos personajes de la historia de Castilla de los siglos XII y XIII.

Por otra parte, al ser explícitamente reconocida la posción

\footnotetext{
87 AGS, Patronato Real, 39-90.
} 
preeminente de los duques, la comunidad monástica quedó obligada a observar una serie de rituales en sus relaciones públicas con ellos, que fueron fijados por escrito en documentos de los que aún se conserva algún ejemplar en el archivo monástico, que recogen el ceremonial que se había de seguir. En el acuerdo de 1633 también se hizo alusión explícita a esta cuestión, aunque limitándose a disponer que cuando los duques acudiesen al monasterio a visitarlo por primera vez, después de haber accedido al gobierno del estado o tras una prolongada estancia fuera del reino, se les recibiese por la comunidad en la misma forma que se había usado con sus antepasados. Para evitar, sin embargo, que las ceremonias pudiesen resultar comprometedoras para la supremacía de la dignidad real, Felipe IV, en su condición de patrón del monasterio, confirmó el referido acuerdo con la explícita condición de que en los recibimientos que el convento hubiese de hacer a los duques no pudiesen usar de ceremonias reales.

\section{CONCLUSIÓN}

A principios del siglo XVII, por consiguiente, se puede considerar cerrado el proceso de transformación del monasterio de Santa María de Huerta. Había comenzado siendo una institución pionera, con ambiciones colonizadoras e imbuida por unos ideales de carácter cosmopolita, pues buscaban el reforzamiento de las relaciones entre todos los cristianos del continente europeo sometidos a la autoridad de Roma. Eran los ideales que habían llevado a mediados del siglo XII a un puñado de monjes franceses a abandonar su tierra de origen para instalarse en un lejano espacio recientemente arrebatado al control musulmán, en proceso de organización desde el punto de vista políticojurisdiccional. Durante el resto del período medieval Huerta continuó manteniendo un perfil de comunidad abierta que, aunque sometida a la jurisdicción de los reyes de Castilla, se había preocupado por cuidar también su relación con los monarcas del vecino reino de Aragón, en el que mantuvo fuertes intereses, por localizarse allí una parte importante de su patrimonio. Con el transcurso del tiempo, sin embargo, poco a poco esta amplitud de horizontes se fue restringiendo. Las relaciones con Aragón se fueron debilitando, y mucho más todavía las mantenidas con los cistercienses de allende los Pirineos. Dicho proceso culminó con la consolidación de la Congregación observante del Císter de la Corona de Castilla. Tras su incorporación a la misma a principios del siglo XVI, Huerta fue adquiriendo un perfil cada vez más nítido de monasterio castellano con sus intereses centrados en la Corona de Castilla. Ciertamente continuó conservando una parte importante de su patrimonio aragonés, pero en el siglo XVI se desprendió de uno de los elementos más emblemáticos del mismo, el señorío jurisdiccional de Torrehermosa. Y este repliegue hacia Castilla estuvo también favorecido por la progresiva influencia ejercida sobre la comunidad monástica por los nobles más poderosos de la comarca donde se ubicaba, los señores de Medinaceli. En el transcurso del siglo XV éstos fueron paulatinamente privándola de su capacidad de participar como actor independiente en el escenario político regional, y terminaron convirtiéndola en un mero apéndice de la casa ducal.

\section{BibliografíA}

Abulafia, D. y Berend, N. 2002. Medieval Frontiers: Concepts and practices. Londres: Ashgate.

Alcalde Jiménez, J. M.a 1996. El poder del señorío. Señorío y poderes locales en Soria entre el Antiguo Régimen y el Liberalismo. Valladolid: Junta de Castilla y León.

Álvarez Palenzuela, V. Á. 1978. Monasterios cistercienses en Castilla (Siglos XII-XIII). Valladolid: Universidad.

Ávila Seoane, N. 2009. "Señoríos del monasterio de Santa María de Huerta», en M. I. del Val Valdivieso y P. Martínez Sopena (dirs.), Castilla y el mundo feudal. Homenaje al profesor Julio Valdeón: vol. I, 313-330. Valladolid: Junta de Castilla y León-Universidad de Valladolid.

Barbastro Gil, L. 2000. El monasterio de Piedra (1194-1836). Ayer y hoy de la abadía cisterciense. Alicante: Gráficas Linencop.

Bartlett, R. y Mackay, A. (eds.) 1992. Medieval frontier societies. Oxford: Clarendon Press.

Baury, G. 2012. Les religieuses de Castille. Patronage aristocratique et ordre cistercien, XIIe-XIIle. Siècles. Rennes: Presses Universitaires de Rennes.

Burton, J. E. 2011. The Cistercians in the Middle Ages. WoodbridgeRochester: Boydell Press.

Carretero Zamora, J. M. 2008: La averiguación de la Corona de Castilla 1525-1540. Los pecheros y el dinero del reino en la época de Carlos V: vol. I, 154. Valladolid: Junta de Castilla y León.

Dailliez, L. 1987. Veruela. Monasterio cisterciense. Zaragoza: Diputación Provincial.

De la Fuente Cobos, C. 1993. La vida económica del Monasterio de Piedra en la primera mitad del siglo XIV. Madrid: Universidad Complutense de Madrid.

De la Fuente Cobos, C. 2001. Libro de apeos del Monasterio de Piedra (1344). Libro de cuentas de la bolsería del Monasterio de Piedra (1307-1348). Zaragoza: Institución Fernando el Católico.

Diago Hernando, M. 1991-1992. «Repoblación e integración política en el reino de Castilla del ámbito de la Tierra de Soria». Revista de Investigación del Colegio Universitario de Soria XI (3): 37-58.

Diago Hernando, M. 1992. «El intervencionismo nobiliario en los monasterios riojanos durante la Baja Edad Media. Encomiendas y usurpaciones». Hispania 182: 811-61

Diago Hernando, M. 1996. «Los señoríos monásticos en la Rioja bajomedieval: introducción a su estudio». Berceo 131: 85-107.

Diago Hernando, M. 2005. «Vicisitudes de un gran estado señorial en la frontera de Castilla con Aragón durante la primera mitad del siglo XIV: Los señoríos sorianos del infante Don Pedro». Anuario de Estudios Medievales 35/1: 47-90.

Diago Hernando, M. 2013. "Los efectos de las guerras entre los Trastamara de Castilla y Aragón sobre las comarcas de frontera durante el siglo XV», en I. Falcón (coord.), El compromiso de Caspe (1412), cambios dinásticos y constitucionalismo en la Corona de Aragón: 304-312. Zaragoza: Obra Social de IberCaja.

Diago Hernando, M. 2014. «El papel de la alta nobleza en el proceso de reforma de los monasterios benedictinos de la Corona de Castilla a fines del Medievo», en I. Beceiro Pita (dir.), Poder, Piedad y Devoción. Castilla y su entorno. Siglos XII-XV: 359-388. Madrid: Sílex.

Eberl, I. 2002. Die Zisterzienser: Geschichte eines europäischen Ordens. Stuttgart: Jan Thorbecke Verlag.

Fernández Martín, P. 1963. "Los monasterios de Buenafuente y Santa María de Huerta y el arzobispo Ximénez de Rada». Celtiberia 26: 159-181.

García Luján, F. J. 1981. Cartulario del monasterio de Santa María de Huerta. Soria: Diputación Provincial.

Higes, V. 1958 y 1960. «El censo de Alfonso X y las parroquias sorianas». Celtiberia 20: 97-104 y 225-273.

Jimeno, E. 1958. "La población de Soria y su término en 1270 ». Boletín de la Real Academia de la Historia 152: 230-70 y 365-494.

Ladero Quesada, M. Á. 2001. "Sobre la evolución de las fronteras medievales hispanas (siglos XI a XIV)», en Identidad y representación de la frontera en la España medieval (siglos XI-XIV): 5-49. Madrid: Casa de Velázquez-Universidad Autónoma de Madrid. 
Lekai, L. J. 1977. The Cistercians. Ideals and Reality. The Kent State University Press.

López, C. 1968-1969. «Incorporación de los monasterios cistercienses navarros a la Congregación de la Corona de Aragón». Cuadernos de Historia Jerónimo Zurita 21-22: 207-243.

Martín, E. 1953. Los bernardos españoles. Historia de la Congregación de Castilla de la Orden del Císter. Palencia: Gráficas Aguado.

Moral, T. 1968. «La Congregación cisterciense de la Corona de Aragón y los monasterios navarros entre 1569 y 1632». Príncipe de Viana 110-111: 5-27.

Moreno Lapeña, J. L. 1995. La memoria, el arte y la cultura en la abadía de Santa María de Veruela. Zaragoza: Moreno Twose.

Moxó y Ortiz de Villajos, S. 1969 «De la nobleza vieja a la nobleza nueva. La transformación nobiliaria castellana en la Baja Edad Media». Cuadernos de Historia 3: 1-210.

Pacaut, M. 1993. Les moines blancs. Histoire de l'ordre de Cîteaux. París: Fayard.

Pardo Rodríguez, M.a L. 1993. Documentación del Condado de Medinaceli (1368-1454). Soria: Diputación Provincial.

Pérez-Embid Wamba, F. J. 1986. El Císter en Castilla y León. Valladolid: Junta de Castilla y León.

Redondo Veintemillas, G. y Sarasa Sánchez, E. 1988. «El señorío de Ariza de la familia Palafox y la sentencia de Celada». Jerónimo Zurita. Revista de Historia 58: 31-50.
Rodríguez Lajusticia, S. 2010. El dominio del monasterio de Santa María de Veruela desde su fundación hasta 1400. Zaragoza: Institución Fernando el Católico.

Romero Redondo, A. 1962. «Doña Sancha Gómez, madre de San Martín de Finojosa». Celtiberia 23: 93-116.

Romero Redondo, A. 1976. "Huerta, pueblo y monasterio». Celtiberia 51: 55-68.

Romero Redondo, A., Luzón, L. M.ạ y Anguita Fontecha, A. 2005. Santa María de Huerta. Monasterio Cisterciense. Zaragoza.

Rubio Semper, A. 2006. Libro de la Pecha de la villa de Ateca. Zaragoza: Instituto Fernando el Católico.

Santos Díez, J. L. 1949. La encomienda de monasterios en la Corona de Castilla. Siglos X-XV. Roma-Madrid: CSIC.

Strayer, J. R. 1988. "The Laicization of French and English Society in the Thirteenth Century», en S. L. Thrupp, Change in Medieval Society: 102-125. Toronto-Buffalo-Londres: University of Toronto Press.

Tobin, S. 1995. The Cistercians. Monks and Monasteries in Europe. Londres: The Herbert Press.

Zurita, J. 1980. Anales de la Corona de Aragón. Zaragoza: Institución Fernando el Católico. 